\title{
Causes and consequences of nuclear envelope alterations in tumour progression
}

\author{
Emily S. Bell and Jan Lammerding
}

\begin{abstract}
Morphological changes in the size and shape of the nucleus are highly prevalent in cancer, but the underlying molecular mechanisms and the functional relevance remain poorly understood. Nuclear envelope proteins, which can modulate nuclear shape and organization, have emerged as key components in a variety of signalling pathways long implicated in tumourigenesis and metastasis. The expression of nuclear envelope proteins is altered in many cancers, and changes in levels of nuclear envelope proteins lamins $\mathrm{A}$ and $\mathrm{C}$ are associated with poor prognosis in multiple human cancers. In this review we highlight the role of the nuclear envelope in different processes important for tumour initiation and cancer progression, with a focus on lamins $A$ and $C$. Lamin $A / C$ controls many cellular processes with key roles in cancer, including cell invasion, stemness, genomic stability, signal transduction, transcriptional regulation, and resistance to mechanical stress. In addition, we discuss potential mechanisms mediating the changes in lamin levels observed in many cancers. A better understanding of causeand-effect relationships between lamin expression and tumour progression could reveal important mechanisms for coordinated regulation of oncogenic processes, and indicate therapeutic vulnerabilities that could be exploited for improved patient outcome.
\end{abstract}




\section{Abbreviations}

29 12-LOX, 12-lipoxygenase; 2D, two-dimensional; 3D, three-dimensional; CDK, cyclin-

30 dependent kinase; CSC, cancer stem cell; ECM, extracellular matrix; EDMD, Emery-

31 Dreifuss muscular dystrophy; EMT, epithelial-mesenchymal transition; ERK1/2,

32 extracellular signal-regulated kinase 1/2; ESCRT, endosomal sorting complex required

33 for transport; GI, gastrointestinal; HGPS, Hutchinson-Gilford progeria syndrome; HSP90,

34 heat shock protein 90; INM, inner nuclear membrane; iPSC, induced pluripotent stem

35 cell; JNK, c-Jun N-terminal kinase; KASH, Klarsicht, ANC-1, and Syne homology;

36 LAP2 $\alpha$, lamina-associated polypeptide $2 \alpha$; LINC, linker of nucleoskeleton and

37 cytoskeleton; MAPK, Mitogen activated protein kinase; MEF, mouse embryonic

38 fibroblast; MKL1, Megakaryoblastic leukemia protein-1; MMP, matrix metalloproteases;

39 NAT, N-acetyltransferase; NE, nuclear envelope; ONM, outer nuclear membrane; PI3K,

40 phosphoinositide 3-kinase; PP2A, protein phosphatase 2A; pRB, retinoblastoma protein;

41 SREBP-1, sterol regulatory element-binding protein 1; SRF, serum response factor;

42 SUN, Sad1 and UNC-84; TGF- $\beta$, transforming growth factor- $\beta$; TRF2, telomere repeat-

43 binding protein;

44

45 Keywords

46 Lamins, cancer, signal transduction, cell migration, cell mechanics, gene regulation 


\section{Introduction}

49 It has long been recognized that cancer cells exhibit characteristic changes in the

50 size and shape of their nuclei, and these features serve as important biomarkers in the

51 diagnosis and prognosis of cancer patients (de Las Heras and Schirmer, 2014). The

52 broad prevalence of these changes is particularly intriguing, since nuclear abnormalities

53 are common across a vast spectrum of cancer types, regardless of tissue source,

54 mutational spectrum, and signalling dependencies. The frequency of nuclear alterations

55 would thus suggest that changes in nuclear structure may be critically linked to the

56 transformation process; however, the factors driving these nuclear abnormalities, and

57 the associated functional consequences, are still incompletely understood.

$58 \quad$ Nuclear morphology could be affected by cancer-associated changes in DNA

59 content (aneuploidy) or higher order chromatin organization (Bustin and Misteli, 2016;

60 Reddy and Feinberg, 2013). The composition of the nuclear envelope (NE) that

61 surrounds the DNA can further influence chromatin architecture and mediate changes in

62 nuclear structure (Pombo and Dillon, 2015). In cancer, morphological abnormalities can

63 occur in the NE itself, appearing as irregular folding, deep grooves, and cytoplasmic

64 inclusions, which is in contrast with the generally smooth NE outline of most normal cells

65 (Fischer, 2014). Notably, altered NE morphology is a crucial part of pathologists'

66 assessment of tumour grade, and correlates with prognosis (Bussolati et al., 2014;

67 Bussolati et al., 2008). Some studies even indicate that NE irregularities may be a direct

68 result of oncogene activation, lack of tumour suppressor function, or genomic instability

69 (Boyd et al., 1991; Fischer, 2014; Fischer et al., 1998). Taken together, these findings

70 suggest that changes in the structure and composition of the NE may be regulated

71 events occurring early in the transformation process, and could thus be directly linked to

72 tumourigenesis. 
The NE includes the inner and outer nuclear membranes (INM and ONM,

74 respectively) and associated membrane proteins, the underlying network of intermediate

75 filaments, termed the nuclear lamina, and nuclear pore complexes spanning the NE

76 (Hetzer, 2010) (Fig. 1). The lamina consists mainly of A-type lamins (A and C) and B-

77 type lamins (B1 and B2). Lamins $A$ and $\mathrm{C}$, as well as less abundant isoforms, are

78 alternatively spliced from the LMNA gene, whereas lamins B1 and B2 are encoded by

79 the $L M N B 1$ and $L M N B 2$ genes, respectively. Lamins are type $\mathrm{V}$ intermediate filaments

80 composed of a N-terminal head domain, a rod domain, and a long C-terminal tail

81 containing an immunoglobulin-like domain (Ho and Lammerding, 2012). Lamins form

82 homodimers through coiled-coil interactions. Homodimers organize head-to-tail into

83 polymers, and polymers further assemble in anti-parallel fashion into non-polar filaments

84 (Gruenbaum and Medalia, 2015). Intriguingly, mutations in the LMNA gene cause a wide

85 range of diseases, collectively termed laminopathies, that include Hutchinson-Gilford

86 progeria syndrome (HGPS), dilated cardiomyopathy, and Emery-Dreifuss muscular

87 dystrophy (EDMD) (Schreiber and Kennedy, 2013). Research aimed at understanding

88 treatment options and disease progression of laminopathies has driven the

89 characterization of many cellular functions for A-type lamins, revealing roles in pathways

90 also known to contribute to tumour progression, such as proliferation and genomic

91 instability. In addition to these signalling pathways, the NE also provides physical

92 strength and stability to protect the nucleus (Isermann and Lammerding, 2013;

93 Lammerding et al., 2006). The structural support generated by lamins is particularly

94 important in cell types subjected to greater mechanical stress, such as in skeletal and

95 cardiac tissues (Isermann and Lammerding, 2013; Swift et al., 2013; Zuela et al., 2016;

96 Zwerger et al., 2013). Thus, alterations in the NE could impact both the physical and

97 biochemical properties of cells during tumour initiation and progression. 
Strengthening the potential connection between NE proteins and tumourigenic

99 processes, altered NE protein expression has been detected in many human cancers

100 and can have prognostic significance (reviewed in Denais and Lammerding (2014) and

101 Chow et al. (2012)). For example, decreased expression of lamin A/C is found in many

102 prostate, breast, colon, ovarian, and gastric cancers and is associated with worse

103 prognosis (Belt et al., 2011; Gong et al., 2015; Matsumoto et al., 2015; Saarinen et al.,

104 2015; Wu et al., 2009). Conversely, studies on colorectal and prostate tumours have

105 identified an association between increased expression of lamin A/C and disease

106 progression (Kong et al., 2012; Willis et al., 2008). These studies indicate that the role of

107 A-type lamins in cancer is likely context-dependent, and further studies are required to

108 determine how lamins function in cancer progression in different cell types, mutational

109 backgrounds, and stages of disease. Furthermore, despite the widely documented

110 changes in NE composition in cancer, few studies have been able to directly connect

111 factors initiating alterations in the NE to functional consequences in malignant cell

112 behaviours. Thus, there is a need to understand the cause-and-effect relationships

113 between changes in NE structure and composition and the tumourigenic process.

114 Although many NE proteins are altered in cancer and likely contribute to tumourigenesis

115 and cancer progression, this review focuses mainly on how A-type lamins and their

116 interaction partners could act as a key point of dysregulation in cancer, and promote

117 growth and metastasis through effects on cell structure, signalling, genomic stability, and

118 gene expression.

120 The nuclear envelope in migration, invasion, and metastasis

121 Invasive behaviour is one of the hallmarks of cancerous cells (Hanahan and

122 Weinberg, 2011). Cancer cell invasion contributes to the spread of tumour growth to

123 additional tissues, termed metastasis, which is the main cause of morbidity and mortality 
124 in most cancers (Talmadge and Fidler, 2010). During in vivo migration, cells navigate

125 through spaces in extracellular matrix (ECM) and cellular environments as small as $2 \mu \mathrm{m}$

126 in diameter, which is substantially smaller than the size of the nucleus (Stoitzner et al.,

127 2002; Weigelin et al., 2012). Cells can navigate these tight spaces by remodeling ECM

128 fibers to modify their environment, including through ECM degradation by secreted

129 matrix metalloproteases (MMPs), which are upregulated in many cancers and

130 associated with poor prognosis (Coussens et al., 2002). Alternatively, cells can deform to

131 squeeze through the available space (McGregor et al., 2016). This versatility may have

132 contributed to the failure of MMP inhibitors to improve patient outcome in clinical trials

133 (Coussens et al., 2002). While the dynamic cytoplasm deforms easily to fit through

134 micron-scale spaces, the nucleus is the largest and stiffest cellular organelle, and

135 nuclear deformation can impose a rate-limiting step on migration in 3D environments

136 (McGregor et al., 2016; Wolf et al., 2013). Accordingly, cells migrating in 3D collagen

137 matrices show extensive nuclear deformation when MMP activity is inhibited, and

138 sufficiently small pore sizes can lead to complete stalling of cell movement as the

139 nucleus becomes 'trapped' in the dense network (Wolf et al., 2013). The deformability of

140 the nucleus is largely determined by expression of A-type lamins (Lammerding et al.,

141 2006; Lammerding et al., 2004; Pajerowski et al., 2007; Schape et al., 2009), although

142 changes in B-type lamin expression can also impact nuclear elasticity (Ferrera et al.,

143 2014; Swift et al., 2013). As a result, cells with decreased lamin A/C levels migrate

144 significantly faster through narrow constrictions in microfluidics devices and transwell

145 plates with $3 \mu \mathrm{m}$ pore sizes (Davidson et al., 2014; Harada et al., 2014; Shin et al.,

146 2013). Consistent with these findings, cells in the periphery of a xenograft tumour model

147 showed more nuclear deformation and lower lamin A expression relative to cells in the

148 tumour core, suggesting that subpopulations of cells with lower lamin A were more

149 efficient at invasion in vivo (Harada et al., 2014). The importance of lamin A/C levels in in 
150 vivo cell migration is further exemplified in neutrophils, where maintaining nuclear

151 deformability is critical for passage through narrow capillaries less than one-fifth of the

152 cell diameter (Doerschuk et al., 1993). A-type lamins are normally downregulated during

153 neutrophil differentiation (granulopoiesis), and ectopic expression of lamin A in

154 neutrophil-type cells impairs their ability to pass through micron-scale constrictions

155 (Rowat et al., 2013). These studies demonstrate the importance of lamin A/C-dependent

156 nuclear stiffness in normal physiology and cancer cell invasion.

157 Interestingly, decreased lamin A/C expression may facilitate migration in confined

158 space, but also renders cells more susceptible to physical stress. This is particularly

159 relevant for cancer cells subjected to changing physical conditions, such as increased

160 hydrostatic pressure within the tumour, mechanical stress associated with migration

161 through tight interstitial spaces, and fluid shear stress in the circulatory system.

162 Increased nuclear fragility and NE rupture has been reported in lamin A/C-deficient and

163 lamin mutant models for laminopathies (Broers et al., 2004; De Vos et al., 2011;

164 Lammerding et al., 2004; Vargas et al., 2012). The NE has a critical role in protecting the

165 genome, and loss of NE integrity could damage DNA and potentially lead to cell death

166 (Denais et al., 2016; Raab et al., 2016). Cells expressing less lamin A/C have a general

167 increased sensitivity to mechanical stress, as cells with reduced lamin $A / C$ levels exhibit

168 more cell death in response to mechanical strain (Lammerding et al., 2004), fluid shear

169 stress (Mitchell et al., 2015), and migration through confined spaces (Harada et al.,

170 2014; Raab et al., 2016). However, other studies did not report increased cell death from

171 confined migration (Davidson et al., 2014; Denais et al., 2016; Liu et al., 2015; Rowat et

172 al., 2013), indicating that different cell types or experimental conditions may impact the

173 specific sensitivity to mechanical stress in confined spaces. Recent work from our lab

174 and others has shed additional light on the potential consequences of nuclear

175 deformation in confined migration. Migration through tight spaces in vitro and in vivo 
176 resulted in rupture of the NE in a broad panel of cell types, and the incidence of NE

177 rupture increased dramatically with smaller pore sizes and depletion of lamins (Denais et

178 al., 2016; Harada et al., 2014; Raab et al., 2016). NE rupture was characterized by

179 uncontrolled exchange of material between the nucleus and cytoplasm, chromatin

180 herniation into the cytoplasm, and DNA damage (Denais et al., 2016; Raab et al., 2016).

181 Strikingly, the majority of cells survive these NE rupture events, but survival requires

182 rapid ESCRT (endosomal sorting complex required for transport)-dependent NE repair

183 and intact DNA damage repair machinery (Denais et al., 2016; Raab et al., 2016). In

184 cancer cells, migration-induced DNA damage could further contribute to genomic

185 instability and thereby promote cancer progression. However, nuclear rupture could also

186 be a unique vulnerability of metastasizing cancer cells, such that targeting NE repair and

187 DNA damage repair in these cells could have therapeutic value.

188 In addition to protecting the nuclear content, lamins and associated LINC

189 complex proteins also play important roles in organizing cytoskeletal structure,

190 dynamics, and polarity, which are important for cell migration. Interrupting nucleo-

191 cytoskeletal coupling by disruption of the LINC-complex or lack of A-type lamins results

192 in altered organization of actin, tubulin, and vimentin networks and impaired cell

193 polarization and 2D cell migration, although effects on migration vary across different

194 studies (Broers et al., 2004; Davidson et al., 2014; Houben et al., 2009; Lee et al., 2007;

195 Lombardi et al., 2011; Razafsky et al., 2014). Increased levels of lamin A can also

196 promote migration of colorectal cancer cells through increased expression of T-plastin,

197 which downregulates E-cadherin, a key cell-cell adhesion molecule frequently absent in

198 cancer (Willis et al., 2008).

199 Taken together, these studies indicate that lamin A/C expression may be a

200 double-edged sword: low levels promote cell invasion through increased nuclear

201 deformability, while high levels protect against mechanical forces, such as increased 
202 interstitial pressure within the tumour, and some minimum function of lamins is required

203 for proper cell polarization and cytoskeletal organization. In addition, cell viability in

204 response to strain or after rupture may depend on other functions of lamin $A / C$ that

205 impact signalling pathways or DNA damage repair (discussed below). Thus, the effect of

206 A-type lamin levels on migration and metastasis is likely context-dependent, favoring

207 high or low expression in different cancer types or stages of disease.

209 Lamin A/C and cancer stem cells

210 A-type lamin expression also has important effects in the context of pluripotent

211 stem cells and differentiation. The association of changes in lamin expression with the

212 progression from a stem cell to a differentiated state was first described during mouse

213 development. Lamin A/C levels are absent in embryonic stem cells, and mice lacking A-

214 type lamins undergo seemingly normal embryonic development (Constantinescu et al.,

215 2006; Stewart and Burke, 1987; Sullivan et al., 1999). However, A-type lamins are

216 required for postnatal growth, and A-type lamin expression increases with differentiation,

217 not appearing in some tissues until after birth (Rober et al., 1989; Sullivan et al., 1999).

218 In adult mouse tissues, cell types that exhibit more stem cell or proliferative properties

219 also retain low lamin $\mathrm{A} / \mathrm{C}$ levels, which is in contrast to the higher lamin $\mathrm{A} / \mathrm{C}$ expression

220 detected in most somatic cells and tissues (Broers et al., 1997; Rober et al., 1990; Swift

221 et al., 2013; Takamori et al., 2007). The inverse association between lamin A/C levels

222 and stem cell characteristics is further illustrated in in vitro differentiation and stem cell

223 induction assays. Somatic cells treated to induce pluripotency show loss of lamin A/C

224 expression, demonstrating that lamin levels are not static but scale reversibly with the

225 degree of differentiation (Alberio et al., 2005; Bru et al., 2008). Conversely, somatic cells

226 expressing higher levels of lamin A show decreased efficiency in reprogramming to

227 induced pluripotent stem cells (iPSCs), and experimental manipulation to increase or 
228 decrease lamin A levels results in reduced or enhanced induction of iPSCs, respectively, 229 suggesting that levels of lamin A in somatic cell populations reflect varying degrees of 230 plasticity (Zuo et al., 2012). In addition, overexpression of lamin A in normal human

231 fibroblasts results in decreased replicative lifespan (Candelario et al., 2008).

232 Furthermore, overexpression of lamin A/C impairs adipogenic conversion of pre-

233 adipocytes (Boguslavsky et al., 2006), possibly due to the requirement to remodel the 234 nuclear lamina during adipogenesis (Verstraeten et al., 2011). These studies show that 235 lamin $\mathrm{A} / \mathrm{C}$ expression is not just a marker of differentiation, but also actively contributes 236 to lineage commitment and loss of phenotypic plasticity.

237 The function of lamin $A / C$ in differentiation can be attributed in part to the ability 238 of lamin $A / C$ to interact with chromatin and influence the structural organization of the 239 nucleus. Interactions between chromatin and lamins change during differentiation and 240 play an important role in lineage determination (Lund et al., 2013; Peric-Hupkes et al.,

241 2010). Increased NE shape fluctuations are an identifying feature of mesenchymal stem

242 cells, and lack of lamin A/C has been shown to increase both nuclear deformations and

243 chromatin dynamics (Bronshtein et al., 2015; Lee et al., 2014; Makhija et al., 2016).

244 Hundreds of genomic regions termed lamina-associated domains (LADs) interact with

245 the lamina and typically exhibit transcriptional repression (Guelen et al., 2008). Artificial

246 tethering to the lamina can downregulate expression of targeted genes, and directing

247 lamin A to promoter regions results in transcriptional repression (Finlan et al., 2008; Lee

248 et al., 2009; Reddy et al., 2008). Transcriptional silencing of chromatin tethered to the

249 lamina is mediated at least in part by epigenetic modifications associated with

250 heterochromatin (reviewed in Gruenbaum and Foisner (2015)), and many proteins

251 involved in epigenetic silencing interact with NE proteins (Guarda et al., 2009; Somech

252 et al., 2005; Zhong et al., 2005). Accordingly, correct expression levels of A-type lamins

253 are required for normal chromatin organization and control of gene expression during 
254 differentiation (Frock et al., 2006; Solovei et al., 2013). Increased lamin A/C levels in 255 differentiated cells could thus solidify phenotypic reprogramming by locking in tissue-

256 specific patterns of heterochromatin at the nuclear periphery; conversely, lamin A/C

257 deficiency is associated with loss of heterochromatin markers (Gonzalo, 2014). It is

258 interesting to consider these mechanisms in the context of epigenetic alterations

259 associated with tumourigenesis (Esteller, 2008; Galiova et al., 2008; Scaffidi and Misteli, 260 2005).

261 The involvement of lamin A/C in cellular differentiation and self-renewal is of 262 particular importance when considering the function of lamins in cancer. The cancer 263 stem cell (CSC) model describes a subset of cells in a tumour that have the ability to 264 continually self-renew and to differentiate into a heterogeneous population (Medema, 265 2013). The phenotypic flexibility and renewal potential from these CSCs, also called 266 tumour-initiating cells, can mediate tumour growth, therapeutic resistance, and 267 completion of the metastatic cascade (Vermeulen et al., 2012), motivating research 268 efforts to define, identify, and treat the stem cell-like population in human cancers. In 269 addition to regulating chromatin organization, the role of lamin $A / C$ in determining cellular 270 plasticity may also involve reprogramming of signalling pathways known to be important 271 for stemness, such as Wnt/ $\beta$-catenin, TGF- $\beta$, and Notch, which are discussed further in 272 sections below. These pathways are already implicated in stem cell phenotypes in 273 cancer, but studies have yet to address the potential involvement of lamin A/C in the 274 CSC phenotype promoted by these signalling events. Nonetheless, Nardella et al.

275 (2015) demonstrated that depletion of A-type lamins in a neuroblastoma cell line resulted 276 in a cell subpopulation with enhanced stem cell characteristics. The authors suggest that 277 this phenotype was mediated by altered expression of microRNA-101, which results in 278 upregulation of the MYC proto-oncogene, and reveals an inverse correlation between 279 expression of lamin A/C and MYC in human neuroblastoma biopsies (Nardella et al., 
2015). Based on our emerging understanding of lamins and their role in stemness and

281 differentiation, the decreased levels of lamin $\mathrm{A} / \mathrm{C}$ in human cancers may both reflect and

282 promote CSC qualities for proliferation and differentiation, which can determine tumour

283 growth, metastasis, and response to therapeutics.

284 As some tumours exhibit increased expression of A-type lamins, it will be

285 interesting to determine whether these tumours still contain a subpopulation of CSCs

286 with lower expression of lamin A/C. Since increased lamin levels could also potentially

287 promote stemness though regulation of signalling and transcription, it will be relevant to

288 determine whether high, rather than low, levels of A-type lamins typify stem cell

289 populations in a particular cancer tissue of origin. Thus, high expression of lamins in

290 such cancers could reflect activation of a stem cell program specific to that tissue. This

291 appears to be the case in colorectal cancer, where the colon stem cell niche stains

292 strongly for lamin A, and increased A-type lamin expression has been associated with

293 aggressive cell behaviour and poor outcome (Willis et al., 2008). In contrast, lamin A/C

294 expression is absent from gastrointestinal (Gl) tract stem cells, and a mouse model of

295 Gl-specific Lmna deletion showed enhanced polyp growth in response to oncogenic

296 stimulus (Wang et al., 2015). These studies highlight the multi-faceted role of lamins in

297 cancers, and demonstrate that the cell type of origin could impact the functional

298 consequences of lamin A/C expression.

\section{A-type lamins in DNA damage and genome stability}

301 The role of the nuclear lamina in physically protecting the nucleus, tethering

302 chromatin, and regulating protein complexes, including components of the DNA damage

303 repair machinery, provides a central position for lamins in the maintenance of genome

304 integrity. Genomic instability is a hallmark feature of most cancers and drives tumour

305 evolution and progression. Maintaining genome integrity has a key role in the 
306 suppression of cancer, which is evident in both the tumour suppressor function of DNA

307 damage checkpoint proteins and the existence of hereditary cancers arising from

308 mutations in DNA repair genes (Negrini et al., 2010).

309 The importance of lamins in maintaining genomic stability is apparent in studies

310 of laminopathy disease progression (reviewed in Gonzalo (2014)). Lamin A/C-mutant

311 and -deficient models exhibit misshapen nuclei, loss of heterochromatin markers,

312 accumulation of unrepaired DNA damage, and chromosomal abnormalities (Gonzalo,

313 2014; Hutchison, 2011; Lammerding et al., 2004). There are diverse mechanisms

314 through which lamins can contribute to genomic stability. Lamin $A / C$ stabilizes the

315 interaction of telomere repeat-binding protein 2 (TRF2) with telomeres, which influences

316 length and protection of telomeric DNA at the ends of chromosomes (Wood et al., 2014).

317 Loss of lamin $\mathrm{A} / \mathrm{C}$ alters positioning of telomeres in the nucleus and results in telomere

318 shortening, which promotes genomic instability (Gonzalez-Suarez et al., 2009; Wood et

319 al., 2014). However, telomere shortening is also considered tumour-suppressive, since

320 telomere maintenance is required for continued DNA replication and cell immortalization,

321 and is often mediated in cancer by activation of the telomerase enzyme (Harley, 2008).

322 TRF2 is a potential oncogene upregulated in some cancers, and TRF2 overexpression

323 can maintain telomere length independently of telomerase through facilitating telomere

324 recombination events, which also foster chromosomal instability (Blanco et al., 2007). It

325 is tempting to speculate that lamin A/C may be required in TRF2-dependent tumours for

326 TRF2 to function in telomere maintenance. Therefore, both increased and decreased

327 lamin $\mathrm{A} / \mathrm{C}$ expression could potentially contribute to genomic instability through

328 regulation of TRF2. Decreased expression of lamin A/C may also subject cells to

329 increased DNA damage due to enhanced susceptibility to mechanical stress, increased

330 nuclear deformation, and more frequent NE rupture events (Denais et al., 2016; Raab et

331 al., 2016). Furthermore, loss of lamin $A / C$ impacts chromatin organization, gene 
332 silencing, and gene positioning, and may therefore increase DNA translocations, which

333 occur more often in transcriptionally active regions and between chromosomes in close

334 proximity (Chiarle et al., 2011; Parada et al., 2004). Cells with loss or mutation of lamin

$335 \mathrm{~A} / \mathrm{C}$ also show separation of chromatin into nuclear blebs or fragments, which could

336 further promote chromosomal instability (Denais et al., 2016; Hatch et al., 2013;

337 Lammerding et al., 2006; Vigouroux et al., 2001). Interestingly, treatment of laminopathic

338 cells with the $N$-acetyltransferase (NAT) 10 inhibitor, remodelin, restores nuclear shape

339 and decreases DNA damage, supporting the idea that genomic instability could be a

340 direct consequence of altered lamin $\mathrm{A} / \mathrm{C}$ levels and aberrant nuclear structure in cancer

341 (Larrieu et al., 2014).

342 Altered lamin levels can also impact the ability of cells to repair DNA damage,

343 potentially accelerating mutagenesis and enhancing tumour initiation and progression.

344 Disruption of lamin A/C increases sensitivity of cells to DNA damaging agents and

345 enhances activation of p53 signalling and p53-dependent senescence (Liu et al., 2005;

346 Singh et al., 2013; Varela et al., 2005). Because p53 is frequently mutated in cancers

347 and therefore unable to suppress growth in response to unrepaired DNA damage,

348 genomic instability caused by altered lamin $A / C$ levels could contribute to tumour

349 progression rather than senescence in cancer cells (Muller and Vousden, 2014). Lamin

$350 \mathrm{~A} / \mathrm{C}$ expression may further impact DNA repair responses through regulation of $\mathrm{p53-}$

351 binding protein-1 (53BP1), a DNA repair protein and potential tumour suppressor (Ward

352 et al., 2003). Mouse embryonic fibroblasts (MEFs) and human fibroblasts both show

353 decreased 53BP1 stability upon lamin A/C deficiency, leading to defects in DNA repair

354 (Gibbs-Seymour et al., 2015; Gonzalez-Suarez et al., 2009; Redwood et al., 2011).

355 Furthermore, 53BP1 interacts with lamin A/C, and depletion of lamin $A / C$ decreases

356 recruitment of remaining 53BP1 to sites of DNA damage and decreases cell viability in

357 response to DNA damage (Gibbs-Seymour et al., 2015). This suggests that loss of lamin 
$358 \quad \mathrm{~A} / \mathrm{C}$ can promote genomic instability through effects on both activity and protein levels of $35953 \mathrm{BP} 1$.

360 Lamin A/C also interacts with proteins involved in chromatin remodeling, such as

361 HDAC1 and RBBP4, and altered epigenetic modifications of chromatin can diminish

362 recruitment of components of the DNA repair machinery and contribute to the

363 accumulation of DNA damage (Krishnan et al., 2011; Pegoraro et al., 2009).

364 Interestingly, depletion of A-type lamins also decreases levels of heat shock protein 90

365 (HSP90), which is a molecular chaperone implicated in DNA damage repair (Harada et

366 al., 2014). However, as a chaperone protein facilitating protein homeostasis, HSP90 also

367 has pro-tumourigenic effects on survival and growth of cancer cells expressing mutated

368 and oncogenic proteins (Trepel et al., 2010). Thus, lower levels of lamin A/C may be

369 detrimental to the growth of tumours driven by HSP90 client proteins, which may explain

370 the increased lamin $\mathrm{A} / \mathrm{C}$ levels observed in some cancers. In considering the role of

371 lamin A/C-related signalling networks in cancer therapy, it will be important to determine

372 whether tumours with low lamin $A / C$ levels show enhanced sensitivity to treatment with

373 either DNA damaging agents or inhibitors of DNA repair pathways.

374

375 Lamin A/C interplay with oncogenes and tumour suppressors

376 Recent studies suggest that lamins and other NE proteins can serve as a hub

377 and modulator for numerous important signalling pathways, such as growth factor-

378 induced kinase signalling and the transcriptional regulation of cell cycle progression

379 (Andres and Gonzalez, 2009). Importantly, these pathways also contribute to many of

380 the hallmarks of cancer, including self-sustained proliferation, insensitivity to anti-growth

381 signals, evasion of apoptosis, limitless self-renewal potential, and invasion and

382 metastasis (Fig. 2). We briefly highlight the role of lamins in some of the most relevant

383 pathways below. 
Inactivation of the retinoblastoma protein $(\mathrm{pRB})$ is a widespread feature of human cancers (Johnson et al., 2016). The tumour suppressor function of $p R B$ is attributed to its

388 role in regulating cell proliferation. pRB binds to the E2F transcription factor, resulting in

389 repression of genes involved in cell cycle progression and DNA replication. The cyclin-

390 dependent kinase (CDK)-mediated phosphorylation of pRB causes release of E2F,

391 increased E2F transcriptional activity, and G1-S cell cycle progression (Giacinti and

392 Giordano, 2006). Recent studies indicate that lamins A/C and the lamina-associated

393 polypeptide $2 \alpha($ LAP2 $\alpha$ ) exert an additional layer of control on $p R B$. Lamin A/C tethers

394 pRB either through direct interaction or in complex with LAP2 $\alpha$, promoting accumulation

395 of hypophosphorylated pRB and delay of cell cycle entry (Dorner et al., 2006; Markiewicz

396 et al., 2002; Van Berlo et al., 2005). Furthermore, in the absence of lamin A/C, pRB is

397 mislocalized and targeted for proteasomal degradation, suggesting that depletion of

398 lamin $\mathrm{A} / \mathrm{C}$ could promote increased proliferation through loss of the $\mathrm{pRB}$ checkpoint

399 (Johnson et al., 2004). Accordingly, lamin A/C-deficient MEFs exhibit increased cell

400 cycle progression, and depletion of lamin A/C in a human lung cancer cell line increased

401 in vivo tumour growth rate (Harada et al., 2014; Johnson et al., 2004). In contrast,

402 depleting lamin $A / C$ in primary human diploid fibroblasts results in $\mathrm{G}_{1}$ arrest,

403 demonstrating cell type-dependent effects of lamin A/C levels on proliferation (Pekovic et

404 al., 2007). The pRB/E2F and p53 tumour suppressor pathways are interconnected,

405 suggesting that mutation of p53 in cancer cells may account for some of the context-

406 dependent effects on proliferation observed with loss of lamin A/C (Muller and Vousden,

407 2014; Polager and Ginsberg, 2009). Additional NE components may also influence the

408 role of LAP2 $\alpha$ and lamin A/C in pRB regulation, as lack of the INM protein emerin has

409 been associated with diminished ability of pRB to repress transcription (Melcon et al., 
410 2006). Finally, it is worth noting that multiple studies in cell lines and tissues support an

411 inverse relationship between lamin A/C levels and proliferation, which is consistent with

412 the association of increased lamin A/C with differentiation (Broers et al., 1997; Ivorra et

413 al., 2006; Nitta et al., 2006; Van Berlo et al., 2005). Thus, dysregulation of pRB and

414 increased cell proliferation could be a key consequence of lamin $A / C$ alterations in

415 cancer, particularly in cells lacking functional p53.

416

$417 \underline{\text { Wnt/3-catenin }}$

418 The Wnt proto-oncogene is a secreted factor that binds to the Frizzled receptor to

419 promote stabilization of $\beta$-catenin, which is followed by $\beta$-catenin nuclear translocation

420 and regulation of transcription (reviewed in Clevers and Nusse, 2012). The Wnt/ $\beta$ -

421 catenin pathway is implicated in promoting CSCs and epithelial-mesenchymal transition

422 (EMT) in cancer, which has driven the development of therapies targeting Wnt pathway

423 (Takebe et al., 2015). Recent studies indicate that several NE proteins interact with $\beta$ -

424 catenin and can modulate $\mathrm{Wnt} / \beta$-catenin signalling. Emerin interacts with $\beta$-catenin and

425 represses its activity through negative regulation of nuclear accumulation (Markiewicz et

426 al., 2006). Loss of emerin results in $\beta$-catenin nuclear localization and hyperactivation

427 (Markiewicz et al., 2006; Stubenvoll et al., 2015). Lamin A directly interacts with emerin

428 and is required for its NE localization, and lamin A/C has also been identified in complex

429 with $\beta$-catenin (Bermeo et al., 2015; Vaughan et al., 2001). However, lamin A/C

430 expression increases nuclear translocation and activity of $\beta$-catenin, and lamin $A / C$

431 mutations inhibit $\mathrm{Wnt} / \mathrm{\beta}$-catenin activity in mouse models of the segmental aging disease

432 HGPS (Bermeo et al., 2015; Espada et al., 2008; Hernandez et al., 2010). The KASH

433 domain protein, Nesprin-2, also interacts with emerin and $\beta$-catenin, and depletion of

434 Nesprin-2 reduces $\beta$-catenin nuclear translocation and activity, demonstrating an

435 additional layer of complexity in NE-mediated regulation of $\beta$-catenin (Neumann et al., 
436 2010). Moreover, the $\mathrm{Wnt} / \beta$-catenin pathway also modulates expression of NE proteins,

437 as depletion of $\beta$-catenin decreases emerin gene expression and increases lamin $A / C$

438 expression (Tilgner et al., 2009). These studies demonstrate complex, bi-directional

439 interplay between $\beta$-catenin and the NE and stimulate further investigation to determine

440 whether alterations in NE-mediated regulation of $\beta$-catenin also occur in tumourigenesis,

441 and whether such changes could contribute to maintenance of the CSC population and

442 EMT.

$444 \quad \underline{M A P K}$

$445 \quad$ Mitogen activated protein kinase (MAPK) signalling kinases phosphorylate both

446 cytoplasmic and nuclear targets to modulate diverse cellular processes related to

447 malignant transformation (Dhillon et al., 2007). Dysregulation of MAPK signalling is a

448 common feature in cancer, often occurring downstream of growth factor signalling or

449 through mutation (Dhillon et al., 2007). Interestingly, loss of lamin A/C or emerin, as well

450 as expression of lamin $\mathrm{A} / \mathrm{C}$ mutations associated with muscular dystrophy and dilated

451 cardiomyopathy, result in hyperactivation of multiple MAPK signalling branches, namely

452 extracellular signal-regulated kinase 1/2 (ERK1/2), c-Jun N-terminal kinase (JNK), and

453 p38a MAPK (Emerson et al., 2009; Muchir et al., 2007; Muchir et al., 2012a; Muchir et

454 al., 2012b; Muchir et al., 2009). The molecular mechanism by which lamin A/C and

455 emerin can modulate MAPK signalling remains incompletely understood. A-type lamins

456 interact directly with ERK1/2 and c-fos, resulting in ERK1/2-dependent release of the c-

457 fos transcription factor from lamin A/C and activation of AP1-mediated transcription and

458 proliferation (Gonzalez et al., 2008). Competitive ERK1/2 binding to lamin A may also

459 regulate cell cycle progression through displacement and inactivation of pRB (Rodriguez

460 et al., 2010). Interestingly, lamin A was also found to interact with protein kinase C

461 (PKC)a, which is a serine-threonine kinase implicated in MAPK activation and cancer 
462 progression (Haughian et al., 2009; Martelli et al., 2002; Mauro et al., 2002). Translating

463 these findings to signalling in the context of cancer cells could be an important step in

464 determining the role of lamin $\mathrm{A} / \mathrm{C}$ alterations in tumour progression. Inhibitors of the

465 MAPK pathway are in clinical trials for cancer treatment, raising the question of whether

466 levels of A-type lamins could have prognostic value for response to MAPK inhibition

467 (Roberts and Der, 2007).

468

$469 \underline{\text { PI3K/AKt }}$

$470 \quad$ The phosphoinositide 3-kinase (PI3K)/Akt signalling network, which controls

471 cancer cell proliferation, metabolism, and invasion, is the most frequently altered

472 pathway in human cancers, making it a focus for targeted therapeutics (Fruman and

473 Rommel, 2014). Increased PI3K/Akt activity can result from alterations in GTPase or

474 tyrosine kinase signalling inputs, activating PI3K/Akt mutations, or loss of negative

475 regulators, such as the PTEN lipid phosphatase (Engelman, 2009). However, it remains

476 unclear what role lamins play in Akt-mediated cellular responses, particularly in the

477 context of cancer. Interestingly, the heart and muscle of lamin A/C-deficient mice show

478 hyperactivation of mammalian target of rapamycin complex 1 (mTORC1), which is a

479 downstream target of Akt (Ramos et al., 2012). In contrast, increased levels of lamin A/C

480 were found to positively regulate the PI3K/Akt pathway in prostate cancer, where lamin

481 A/C expression has been associated with higher risk tumours (Kong et al., 2012;

482 Skvortsov et al., 2011). Low grade prostate cancers showed very little lamin A/C,

483 suggesting that the pro-tumourigenic function of lamin $\mathrm{A} / \mathrm{C}$ may arise in cooperation with

484 other changes associated with high grade tumours, rather than as a general feature of

485 prostate cancer.

486

$487 \quad \underline{T G F-\beta}$ 
489 to activate Smad-dependent and Smad-independent signalling cascades (Moses and

490 Barcellos-Hoff, 2011). Phosphorylation of Smads results in dimerization and

491 translocation into the nucleus, where they act as co-activators and co-repressors

492 interacting with an extensive collection of transcription factors (Ten Dijke et al., 2002).

493 The outcome of TGF- $\beta$ signalling is dependent on the transcription factors present and

494 on activation of parallel signalling pathways (Gomis et al., 2006). This allows the TGF- $\beta$

495 pathway to assume diverse, context-dependent roles in tissue development and

496 homeostasis, acting as a mediator of EMT, ECM remodeling, apoptosis, and cell cycle

497 arrest (Wu and Hill, 2009). Despite having tumour suppressive effects at the initiation

498 stage of tumourigenesis, TGF- $\beta$ can drive the progression and metastasis of established

499 tumours and has been pursued as a therapeutic target (Papageorgis, 2015; Siegel et al.,

500 2003; Tang et al., 2003).

501 Increasing findings suggest that A-type lamins and other NE proteins may play a

502 part in determining the biological outcomes of TGF- $\beta$ stimulation. Regulation of $p R B$ is a

503 primary mechanism through which TGF- $\beta$ inhibits proliferation, and the absence of $p R B$

504 can switch TGF- $\beta$ signalling effects from growth-inhibitory to tumour-promoting.

505 Dysregulation of pRB in lamin A/C-deficient MEFs diminishes the ability of TGF- $\beta 1$ to

506 decrease proliferation, and lamin A/C expression is required for TGF- $\beta$-stimulated

507 dephosphorylation of pRB through regulation of protein phosphatase 2A (PP2A) (Van

508 Berlo et al., 2005). Interestingly, lamin A/C levels also impact the kinetics of TGF- $\beta 1$ -

509 induced Smad phosphorylation, with more rapid, intense, and shorter duration

510 phosphorylation of Smad2/3 occurring in the absence of lamin A/C (Van Berlo et al.,

511 2005). Lamin $A / C$ may further co-ordinate responses to TGF- $\beta$ signalling through

512 regulation of other lamina-associated proteins, such as MAN1 and Nesprin-2. MAN1, an

513 integral INM protein, binds directly to Smad2 and Smad3, possibly acting as a 
514 competitive inhibitor of formation of the transcriptionally active complex (Lin et al., 2005).

515 Overexpression of MAN1 is sufficient to inhibit induction of both transcriptional activity

516 and proliferation arrest downstream of TGF- $\beta$ stimulation (Lin et al., 2005). In contrast,

517 Nesprin-2 mediates TGF- $\beta$-induced nuclear translocation of Smad2/3 and c-fos (Rashmi

518 et al., 2012). Therefore, the specific composition of the NE can promote or inhibit

519 aspects of the TGF- $\beta$ signalling program. Interestingly, increasing lamin A expression

520 decreases secretion of TGF- $\beta$, demonstrating both upstream and downstream roles for

521 lamins in TGF- $\beta$ signalling (Evangelisti et al., 2015). Additionally, TGF- $\beta 1$ stimulation

522 was found to reduce the levels of lamin $A / C$ in endothelial cells, and to promote

523 proliferation and migration (Qi et al., 2011). Given the wide variety of phenotypes elicited

524 by TGF- $\beta$, it will be interesting to determine whether changes in lamin levels can control

525 the switch between the growth-suppressive and tumour-promoting effects of TGF- $\beta$ in

526 different stages or types of cancer.

527

$528 \quad$ MKL1/SRF

529 Megakaryoblastic leukemia protein-1 (MKL1, also termed MRTF-A or MAL) is a

530 transcription coactivator of serum response factor (SRF) that regulates expression of

531 genes involved in cell motility, growth, and differentiation (Pipes et al., 2006;

532 Scharenberg et al., 2010). MKL1/SRF signalling has key functions in tumour

533 progression, such as mediating TGF- $\beta$-induced EMT and promoting cell migration and

534 metastasis (Kircher et al., 2015; Medjkane et al., 2009; Morita et al., 2007). MKL1 is

535 localized in the cytoplasm through binding to G-actin, but mitogenic or mechanical

536 stimulation results in actin polymerization and translocation of MKL1 to the nucleus,

537 where it serves a co-factor for SRF to activate expression of numerous proteins involved

538 in cytoskeletal organization, contractility, and adhesion, including integrins, vinculin, and

539 actin (Olson and Nordheim, 2010). MKL1 is also regulated by nuclear actin dynamics, 
540 and loss of lamin $\mathrm{A} / \mathrm{C}$ or emerin from the NE impairs nuclear translocation and signalling

541 of MKL1 due to the role of emerin in controlling nuclear actin polymerization (Baarlink et

542 al., 2013; Ho et al., 2013; Holaska et al., 2004). Consequently, the loss of nuclear

543 accumulation of MKL1 and diminished MKL1/SRF signalling further alters cytoskeletal

544 actin dynamics in lamin A/C- and emerin-deficient cells (Ho et al., 2013). Decreased

545 MKL1/SRF transcriptional activity due to the absence of lamin $A / C$ would be predicted to

546 reduce invasive capabilities of tumour cells, suggesting that this pathway may provide

547 selective pressure to retain a critical amount of lamin $\mathrm{A} / \mathrm{C}$, and select against $L M N A$

548 gene deletions and dominant mutations.

549

$550 \quad$ Additional pathways

551 In addition to the above pathways, lamin A/C has been shown to influence NF-KB

552 transcriptional activity (Lammerding et al., 2004), which can have tumour promoting and

553 tumour suppressive effects (Perkins, 2004). Lamin A/C has also been found to influence

554 the YAP transcriptional coactivator (Bertrand et al., 2014; Swift et al., 2013), which is a

555 major downstream effector of the Hippo pathway and increasingly implicated in tumour

556 progression (Moroishi et al., 2015). Furthermore, lamin A/C mutations responsible for

557 HGPS disturb the Notch pathway (Scaffidi and Misteli, 2008), which is another signalling

558 pathway that can have both oncogenic and tumour suppressor functions (Lobry et al.,

559 2011). A-type lamins were also found to interact with the pro-tumourigenic transcription

560 factors, c-Fos and MYC, and the sterol regulatory element-binding protein 1 (SREBP-1)

561 transcription factor, which is a master regulator of pro-tumourigenic lipid metabolism

562 (Guo et al., 2014; Ivorra et al., 2006; Lloyd et al., 2002; Myant et al., 2015). Interestingly,

563 lamins may also impact tumourigenesis by modulating fatty acid metabolism. Lamin A

564 was identified in a yeast two-hybrid screen for interactors of the pro-tumourigenic

565 enzyme 12-lipoxygenase (12-LOX) (Tang et al., 2000). LOX enzymes are implicated in 
566 carcinogenesis by mediating conversion of polyunsaturated fatty acids into metabolites

567 involved in modulating diverse signalling pathways (Shureiqi and Lippman, 2001). 12-

568 LOX has been implicated in promoting survival, growth, and metastasis in many human

569 cancers (Agarwal et al., 2009; Dilly et al., 2013; Honn et al., 1994; Kerjaschki et al.,

5702011 ; Klampfl et al., 2012). Further study is required to determine whether the regulation

571 of these pathways by lamin $\mathrm{A} / \mathrm{C}$ contributes to tumourigenesis and metastasis.

572

\section{Mechanisms controlling lamin A/C levels in cancer}

$574 \quad$ Mutations in the LMNA gene are responsible for the various laminopathies, but

575 genomic analysis of human tumours suggests that LMNA mutations, deletions, or copy-

576 number variations are not a common feature of most cancers (Fig. 3). However, it is

577 interesting to note the recent identification of a translocation between the tropomyosin-

578 receptor kinase (TRK) and LMNA genes resulting in a fusion product, LMNA-NTRK1, in

579 metastatic colorectal cancer and congenital infantile fibrosarcoma (Sartore-Bianchi et al.,

580 2016; Wong et al., 2016). In both cases, most of the LMNA gene (exons 1-10 or 1-11) is

581 fused to an intact NTRK1 kinase domain, and tumours responded to tyrosine kinase

582 inhibition. However, the mechanistic role of the LMNA portion of the fusion protein in

583 affecting kinase activation, localization, or substrate selection requires further study.

584 Despite the relatively infrequent genomic alterations, changes in lamin A/C expression

585 are common in many cancers at the protein and transcript level, suggesting the

586 involvement of epigenetic, transcriptional, and/or post-translational mechanisms of

587 regulation.

588

$589 \quad$ LMNA gene expression

590 Transcript levels of lamin A/C are governed by epigenetic modifications,

591 transcription factor activity, and microRNAs. The retinoic acid receptor transcription 
592 factors have been shown to act in regulation of lamin A/C (Okumura et al., 2004; Swift et

593 al., 2013), and CpG island promoter hypermethylation is responsible for decreased lamin

$594 \mathrm{~A} / \mathrm{C}$ expression in hematologic cancers and associated with poor prognosis in lymphoma

595 (Agrelo et al., 2005). However, LMNA promoter hypermethylation was not detected in

596 other cancer types, suggesting alternative mechanisms for altered lamin A/C levels in

597 these cases (Agrelo et al., 2005; Lee et al., 2012). One such mechanism could be the

598 microRNA miR-9, which represses lamin A, but not lamin C, in the brain (Jung et al.,

599 2012). Altered miR-9 expression occurs in cancer, and miR-9 has multiple targets that

600 may contribute to tumourigenesis (Cekaite et al., 2012; Lu et al., 2014; Ma et al., 2007).

601 For example, expression of the MYC proto-oncogene in breast cancer cells increases

602 miR-9 expression, which in turn promotes invasion and metastasis through

603 downregulation of the cell-cell adhesion protein, E-cadherin (Ma et al., 2010). Therefore,

604 regulation of lamin A/C by miR-9 may be coordinated as part of a larger metastasis-

605 related signalling network. Akt signalling has also been shown to control LMNA gene

606 expression, demonstrating that multiple signalling programs could contribute to

607 transcriptional regulation of lamin A/C (Bertacchini et al., 2013).

608 Although lamins $A$ and $C$ are both expressed from the $L M N A$ gene, regulation of

609 splicing can control the relative expression levels of these two proteins. Alternative

610 splicing of the LMNA gene contributes to the large variation in tissue-specific differences

611 between expression of lamin A and C (Aljada et al., 2016). Importantly, relative to normal

612 tissues, the ratio of lamin C to lamin A mRNA was found to be elevated in cancers from

613 breast, colon, liver, lung, ovary, thyroid, and prostate (Aljada et al., 2016). Most

614 commonly used antibodies cannot distinguish between lamin A and C, which are

615 identical for the $\mathrm{N}$-terminal 566 amino acids. Nonetheless, differentiating between lamin

616 A and lamin $\mathrm{C}$ will be important when determining the relationship between lamin

617 expression and prognosis, as these isoforms may have distinct effects on cancer 
618 progression. For example, in epithelial ovarian cancer, downregulation of lamin A, but

619 not lamin C, is associated with metastasis and decreased disease-free survival (Gong et

620 al., 2015). These results reveal that regulation of LMNA splicing may play an important

621 role in fine-tuning the properties of the nucleus in different tissues, and may also provide

622 an important point of dysregulation in cancer.

623

624 Post-translational modifications of lamins $A / C$

625 The assembly, function, and stability of lamin $\mathrm{A} / \mathrm{C}$ is also regulated by post-

626 translational modifications. The best characterized lamin post-translational modification

627 is phosphorylation. CDK1- and/or PKC-mediated phosphorylation of lamins disrupts

628 head-to-tail polymer formation promoting lamina disassembly during mitosis (Collas,

629 1999; Peter et al., 1990). There are 61 known lamin A/C phosphorylation sites, with Ser-

630 22, Ser-392, Ser-404, and Ser-406 being key residues for mitotic lamin depolymerization

631 (Simon and Wilson, 2013). Recent studies found that phosphorylation can also modulate

632 lamin assembly and function during interphase (Buxboim et al., 2014; Kochin et al.,

633 2014). Changes in interphase lamin A/C phosphorylation and subsequent degradation in

634 response to substrate stiffness are thought to regulate the stiffness-dependent levels of

635 lamin A/C (Buxboim et al., 2014; Swift et al., 2013). Stiffer matrix and myosin-IIA activity

636 decreases levels of lamin A Ser22 phosphorylation, while cyclin-dependent kinase

637 (CDK)-mediated increases in Ser22 phosphorylation occurred upon reduction of stiffness 638 and nuclear tension (Buxboim et al., 2014).

639 Intriguingly, lamin A is also a nuclear substrate for Akt phosphorylation (Barati et 640 al., 2006; Cenni et al., 2008). Akt-mediated Ser-404 phosphorylation targets prelamin A

641 for degradation, and Akt-mediated degradation of lamin A is important for normal

642 epidermal differentiation (Bertacchini et al., 2013; Cenni et al., 2008; Naeem et al.,

643 2015). Since dysregulated PI3K/Akt signalling is frequently associated with 
644 tumourigenesis, this suggests a potential mechanism for downregulation of lamin $A / C$ in 645 cancer.

646 Other post-translational modifications that could impact lamin $A / C$ assembly and 647 function are ubiquitination, and acetylation, and the covalent addition of small ubiquitin648 like modifier (SUMO) proteins (Simon et al., 2013; Simon and Wilson, 2013; Zhang and

649 Sarge, 2008). Furthermore, the addition of $\beta$ - $O$-linked $\mathrm{N}$-acetylglucosamine, termed $O$ -

650 GlcNAcylation, to lamins has long been recognized, but the impact of this modification

651 on lamin functions remains incompletely understood (Ferraro et al., 1989; Simon and

652 Wilson, 2013). An additional mechanism for post-translational modification of lamins is

653 the oxidation of cysteine residues in the tail domain of lamin A, resulting in disulphide

654 bridges in response to oxidative stress (Pekovic et al., 2011). Thus, there are many

655 possible avenues for post-translationally tuning lamin A/C stability and organization, but

656 a functional understanding of these modifications and their consequences is still lacking.

657

658 Lamins and the mechanical tumour microenvironment

659 It is increasingly becoming apparent that the mechanical tissue microenvironment

660 is playing a crucial role in tumourigenesis and tumour progression (Pickup et al., 2014;

661 Wei and Yang, 2016). The tumour microenvironment is composed of various cell types,

662 ECM proteins, blood vessels, lymphatics, and soluble factors that together create a

663 niche that can support or hinder tumour progression (Quail and Joyce, 2013). During

664 tumourigenesis, remodeling the cellular and ECM architecture in the tissue alters the

665 function of tumour and stromal cells, which can conversely further remodel the

666 microenvironment (Yu et al., 2011). In particular, ECM composition and rigidity modulate

667 signalling pathways associated with tumour progression, such as ERK, TGF $\beta$, and PI3K,

668 thereby affecting EMT and metastasis (Chaudhuri et al., 2014; Leight et al., 2012;

669 Levental et al., 2009; Paszek et al., 2005; Pickup et al., 2014; Wei and Yang, 2016). 
670 Increased stiffness in the stroma surrounding the tumour was shown to accompany

671 tumour progression in a mouse mammary tumour model, and increasing stiffness in vitro

672 is sufficient to convert mammary epithelial cells to an invasive, malignant phenotype

673 (Chaudhuri et al., 2014; Levental et al., 2009; Paszek et al., 2005).

674 Recent studies suggest that lamins could play important roles both upstream and

675 downstream of this mechanosensitive process (Irianto et al., 2016). Since lamins and

676 emerin play a central role in the mechanoregulation of gene expression, changes in

677 lamin levels could influence how cells interpret and respond to changes in their

678 mechanical environment. (Guilluy et al., 2014; Ho et al., 2013; Lammerding et al., 2005;

679 Lammerding et al., 2004). Conversely, a proteomic analysis of soft and stiff tissues

680 revealed that lamin A/C increases with tissue stiffness, whereas B-type lamins exhibited

681 fairly constant abundance, and that the increase in lamin A/C may contribute to lineage

682 specification in differentiation (Swift et al., 2013). Furthermore, xenograft tumours of

683 U251 glioblastoma cells exhibit higher lamin A/C levels when grown in the stiffer

684 subcutaneous flank compared to the brain, suggesting that A-type lamin levels can

685 adjust to tissue stiffness in vivo (Swift et al., 2013). However, it cannot be excluded that

686 lamin $A / C$ levels could be affected by other differences in the properties of these

687 microenvironments, such as levels of tissue-specific growth factors, local metabolite

688 concentrations, or other signaling pathways. In addition to modulating total levels of

689 lamin $\mathrm{A} / \mathrm{C}$, the physical properties of the microenvironment can also affect intranuclear

690 lamina organization. For example, with increased substrate stiffness and cell spreading,

691 a lamin $\mathrm{A} / \mathrm{C}$ conformational epitope in the Ig-domain becomes masked in the basal

692 portion of the NE (Ihalainen et al., 2015), suggesting structural rearrangements within

693 the lamina that could further impact interactions of lamins with chromatin and other

694 binding partners. These studies demonstrate that organization and levels of lamin A/C 
695 are both dynamically regulated in response to the physical microenvironment and can 696 modulate cellular mechanotransduction signalling.

697 Altered lamin A/C levels could in turn influence the microenvironment, as

698 increased collagen deposition and fibrosis are features of multiple laminopathies, and

699 loss of lamin A/C increases collagen production in MEFs (Arimura et al., 2005;

700 Hernandez et al., 2010; Van Berlo et al., 2005; van Tintelen et al., 2007). This suggests

701 that lamin $\mathrm{A} / \mathrm{C}$ levels could respond to cancer-associated changes in the

702 microenvironment to influence not only nuclear structure, but also feedback to remodel

703 the tissue structure and microenvironment. Further research is required to understand

704 how changes in lamin $\mathrm{A} / \mathrm{C}$ contribute to ECM alterations in cancer, and whether the

705 mechanosensitive scaling of lamin A/C remains generally intact in cancer cells and

706 contributes to tumour pathology.

$707 \quad$ Enhanced stiffness in the tumour microenvironment would be expected to affect

708 lamin A/C levels, which could further promote tumour progression. Importantly,

709 increased tissue rigidity is not a uniform characteristic of tumours and has been shown to

710 vary between subtypes and within single tumours (Acerbi et al., 2015). In breast cancers,

711 increased rigidity is commonly observed at the tumour edge, with high stiffness and

712 greater variability in the invasive front (Acerbi et al., 2015; Plodinec et al., 2012;

713 Provenzano et al., 2006). These findings, along with the ability of increased stiffness to

714 promote EMT-like phenotypes, support the hypothesis that tissue rigidity promotes

715 invasion and metastasis (Pickup et al., 2014; Wei and Yang, 2016). However, invasive

716 breast tumours have more heterogeneity in tissue stiffness than benign tumours, which

717 have a more uniform increase in stiffness over normal tissue (Plodinec et al., 2012).

718 Interestingly, studies of stiffness in mouse mammary tumour models found that

719 increased metastasis was associated with more compliant tumours, and lung

720 metastases display lower stiffness than matched primary tumours (Fenner et al., 2014; 
721 Plodinec et al., 2012). The idea that A-type lamins may be regulated by rigidity in these

722 different environments is particularly exciting when viewed from the perspective of lamin

$723 \mathrm{~A} / \mathrm{C}$ controlling differentiation and plasticity. During tumourigenesis, increased tissue-

724 stiffness could modulate lamin $\mathrm{A} / \mathrm{C}$ levels and intranuclear distribution, thereby disturbing

725 chromatin organization and gene expression. During metastasis, outgrowth at the

726 secondary site is thought to be the rate-limiting step in the metastatic cascade, and could

727 require a switch from an EMT to a MET phenotype (Luzzi et al., 1998; Tsai and Yang,

728 2013). Thus, phenotypic flexibility could be the true driver of tumour progression, and

729 may be directly linked to changes in lamin levels and intranuclear organization. In this

730 scenario, it is attractive to imagine that increased rigidity may promote invasion and

731 escape from the primary tumour, but perhaps a softer microenvironment at the

732 secondary site leads to decreased lamin A/C levels that support the enhanced stem cell-

733 associated plasticity required for outgrowth and metastasis (Fig. 4).

\section{Conclusions and future perspectives}

737 Both increased and decreased lamin A/C levels have been associated with poor

738 prognosis in human cancers. This paradox could arise from tissue-specific functions,

739 variation in expression within a single tumour, or dynamic changes in response to

740 biochemical or mechanical signals throughout tumour progression (Fig. 4). Regardless,

741 this discrepancy warrants further investigation to understand in what contexts increased

742 or decreased lamin $\mathrm{A} / \mathrm{C}$ promotes tumour progression. The infrequency of cancer-

743 associated deletions or mutations in the LMNA gene suggests that selective pressures

744 exist for retention of a minimum level of expression or the ability to upregulate lamin $\mathrm{A} / \mathrm{C}$

745 for cellular responses to the changing tumour environment. It is still unclear whether

746 lamin $\mathrm{A} / \mathrm{C}$ levels in cancer are a dynamic representation of conditions in the tumour at a 
747 particular time, and thus a reflection of response to transformed signalling pathways and

748 microenvironmental conditions, or whether altered lamin $\mathrm{A} / \mathrm{C}$ levels in cancer are

749 uncoupled from normal regulatory mechanisms and can independently initiate oncogenic

750 changes.

751 The NE participates in complex regulatory loops, and determining the function of

752 lamin $\mathrm{A} / \mathrm{C}$ in cancer will require studies that can distinguish between the causes and

753 consequences of altered lamin $\mathrm{A} / \mathrm{C}$ in particular tumour types and disease stages. Lamin

$754 \mathrm{~A} / \mathrm{C}$ influences EMT and stem cell phenotypes, which are interconnected cellular

755 programs and important mediators of metastasis and therapeutic resistance (Mani et al.,

756 2008; Shuang et al., 2014). It will be pertinent to determine whether lamin A/C

757 expression in CSCs and metastatic subpopulations is different compared to the bulk

758 primary tumour, and whether this is associated with specific therapeutic vulnerabilities.

759 The use of inducible systems to modify lamin levels at specific stages of in vivo tumour

760 xenograft experiments could be instrumental in answering some of these unresolved

761 questions. Tissue-specific alteration of lamin $\mathrm{A} / \mathrm{C}$ in transgenic mouse models will also

762 be critical to definitively determine the function of lamin A/C during the full scope of

763 disease progression from normal tissue to tumour initiation and through to metastasis.

764 One exciting future direction is the potential exploitation of lamin $\mathrm{A} / \mathrm{C}$ in targeted

765 therapies. It is possible that with a better understanding of lamin $A / C$ regulation and

766 functions, altered lamin levels and organization could serve as a biomarkers for

767 response to specific therapeutics. Lamin A/C influences pathways known to have roles in

768 both tumour suppression and tumour progression, such as TGF- $\beta$, Notch, HSP90, and

769 NF-KB. It is intriguing to imagine that changes in lamin A/C levels and/or organization in

770 cancer act to promote a shift towards the tumourigenic functions of these pathways, and

771 therefore modulating lamin $\mathrm{A} / \mathrm{C}$ expression could be a therapeutic approach for

772 restoration of tumour suppressor function. Additionally, understanding the role of lamin 
$773 \mathrm{~A} / \mathrm{C}$ expression in metastasis could lead to improvements in therapy and patient

774 outcome. For example, cells with lower lamin A/C levels may self-select during invasion

775 in tissue environments due to enhanced nuclear deformability, but are also more

776 susceptible to NE rupture, and may have diminished DNA damage response capabilities.

777 This suggests that inhibiting DNA repair pathways could be an effective strategy to

778 eliminate cells in the process of metastasizing, and tumours with low lamin A/C levels

779 could be particularly susceptible to DNA damaging agents. Thus, while many open

780 questions remain regarding the role of lamins in tumour initiation and progression,

781 rapidly emerging findings suggest that we are entering an exciting area of growth and

782 discovery as lamin $\mathrm{A} / \mathrm{C}$ is increasingly appreciated as a central node regulating multiple

783 aspects of the tumourigenic process, with important diagnostic, prognostic, and

784 therapeutic applications.

785

\section{Acknowledgements}

787 The authors apologize to all researchers whose work could not be cited due to space

788 constraints. This work was supported by awards from the National Institutes of Health

789 [R01 HL082792], the National Science Foundation [CBET-1254846], and the

790 Department of Defense [Breast Cancer Breakthrough BC150580]. The content of this

791 article is solely the responsibility of the authors and does not necessarily represent the

792 official views of the National Science Foundation or the National Institutes of Health.

793

794

$795 \quad$ Figure legends

796

797 Figure 1. Overview of nuclear envelope organization and lamin A/C functions. The

798 nuclear envelope (NE) consists of the outer nuclear membrane (ONM), inner nuclear 
799 membrane (INM), nuclear pore complexes (NPC), nuclear lamina, and additional 800 proteins bound to the lamina and INM. The lamina is a meshwork of intermediate

801 filaments beneath the INM composed of A-type and B-type lamins. Lamins can also 802 localize to the nuclear interior (not depicted here). Lamin $\mathrm{A} / \mathrm{C}$ performs many cellular 803 functions, including providing physical stiffness to protect the nucleus and tethering 804 chromatin into transcriptionally repressed regions at the nuclear periphery. The lamina 805 and associated proteins can also form complexes with signalling molecules to influence 806 nuclear accumulation, stability, and substrate engagement. The nucleus is connected to 807 the cytoskeleton through the linker of nucleoskeleton and cytoskeleton (LINC) complex. 808 The LINC complex is composed of Sad1 and UNC-84 (SUN) domain proteins in the INM 809 that bind to Klarsicht, ANC-1, and Syne homology (KASH) domain proteins that span the

810 ONM and connect to the cytoskeleton, facilitating nuclear positioning and

811 mechanotransduction signalling.

812

813 Figure 2. Connections between lamin A/C and pathways known to suppress or 814 promote cancer formation and progression. Lamin A/C participates in many

815 pathways characterized to have oncogenic (red) or tumour suppressor (blue) functions in 816 cancer. Lamin A/C expression influences protein levels or downstream activity to 817 modulate signal transduction, and in many cases interactions between lamin $\mathrm{A} / \mathrm{C}$ and 818 signalling proteins have also been detected (double lines). It is important to note that 819 many of these functions have been identified in lamin $A / C$ mutant or deletion models for 820 laminopathies, and an understanding of lamin A/C-related signalling in the context of 821 cancer demands further study.

823 Figure 3. Frequency of mutations and copy-number alterations in the LMNA gene

824 in human cancers. The results shown here are based upon data generated by the 
825 TCGA Research Network (http://cancergenome.nih.gov/). Data are presented as

826 analyzed by cBioPortal, accessed April 10, 2016 (http://www.cbioportal.org/) (Cerami et

827 al., 2012; Gao et al., 2013). Shallow loss determined by copy-number analysis is

828 referred to here as "heterozygous deletion" and deep loss is referred to as "homozygous

829 deletion". Copy number variations make up the majority of genomic changes in the

$830 L M N A$ gene in cancer, whereas mutations are rare. It remains to be determined whether

831 LMNA genomic alterations correlate closely with protein levels in cancer, and which

832 transcriptional and/or post-translational mechanisms are important contributors to altered 833 lamin $\mathrm{A} / \mathrm{C}$ expression in cancer.

834

835 Figure 4. Potential roles for lamin A/C in tumour initiation and progression. Both

836 increased and decreased levels of lamin $A / C$ have been observed in cancer and related

837 to patient prognosis. The complexity of lamin A/C functions and signalling networks

838 suggests that the role of lamin $A / C$ in tumour progression may vary with stage of

839 disease, tissue of origin, and mutational landscape of a given tumour. Possible functions

840 for increased and decreased lamin $A / C$ levels during tumour progression are depicted

841 here, and warrant further investigation towards understanding the role of lamin $A / C$ in

842 cancer. Importantly, many of these lamin-related functions could contribute to multiple

843 stages of cancer, but are each shown here only once for simplicity.

844

845 
847 Acerbi, I., Cassereau, L., Dean, I., Shi, Q., Au, A., Park, C., Chen, Y.Y., Liphardt, J.,

848 Hwang, E.S., Weaver, V.M., 2015. Human breast cancer invasion and aggression

849 correlates with ECM stiffening and immune cell infiltration. Integr Biol (Camb) 7, 1120-

8501134.

851 Agarwal, S., Achari, C., Praveen, D., Roy, K.R., Reddy, G.V., Reddanna, P., 2009.

852

853

854

855

856

857

858

859 Inhibition of 12-LOX and COX-2 reduces the proliferation of human epidermoid carcinoma cells (A431) by modulating the ERK and PI3K-Akt signalling pathways. Exp Dermatol 18, 939-946.

Agrelo, R., Setien, F., Espada, J., Artiga, M.J., Rodriguez, M., Perez-Rosado, A., Sanchez-Aguilera, A., Fraga, M.F., Piris, M.A., Esteller, M., 2005. Inactivation of the lamin $\mathrm{A} / \mathrm{C}$ gene by $\mathrm{CpG}$ island promoter hypermethylation in hematologic malignancies, and its association with poor survival in nodal diffuse large B-cell lymphoma. J Clin

Oncol 23, 3940-3947.

860 Alberio, R., Johnson, A.D., Stick, R., Campbell, K.H., 2005. Differential nuclear

861 remodeling of mammalian somatic cells by Xenopus laevis oocyte and egg cytoplasm.

862 Exp Cell Res 307, 131-141.

863 Aljada, A., Doria, J., Saleh, A.M., Al-Matar, S.H., AlGabbani, S., Shamsa, H.B., Al-

864 Bawab, A., Ahmed, A.A., 2016. Altered Lamin A/C splice variant expression as a

865 possible diagnostic marker in breast cancer. Cell Oncol (Dordr) 39, 161-174.

866 Andres, V., Gonzalez, J.M., 2009. Role of A-type lamins in signaling, transcription, and

867 chromatin organization. J Cell Biol 187, 945-957.

868 Arimura, T., Helbling-Leclerc, A., Massart, C., Varnous, S., Niel, F., Lacene, E., Fromes, Y., Toussaint, M., Mura, A.M., Keller, D.I., Amthor, H., Isnard, R., Malissen, M., Schwartz, K., Bonne, G., 2005. Mouse model carrying H222P-Lmna mutation develops muscular dystrophy and dilated cardiomyopathy similar to human striated muscle laminopathies. Hum Mol Genet 14, 155-169.

Baarlink, C., Wang, H., Grosse, R., 2013. Nuclear actin network assembly by formins regulates the SRF coactivator MAL. Science 340, 864-867.

Barati, M.T., Rane, M.J., Klein, J.B., McLeish, K.R., 2006. A proteomic screen identified stress-induced chaperone proteins as targets of Akt phosphorylation in mesangial cells. Journal of Proteome Research 5, 1636-1646.

Belt, E.J., Fijneman, R.J., van den Berg, E.G., Bril, H., Delis-van Diemen, P.M., Tijssen, M., van Essen, H.F., de Lange-de Klerk, E.S., Belien, J.A., Stockmann, H.B., Meijer, S., Meijer, G.A., 2011. Loss of lamin A/C expression in stage II and III colon cancer is associated with disease recurrence. Eur J Cancer 47, 1837-1845.

Bermeo, S., Vidal, C., Zhou, H., Duque, G., 2015. Lamin A/C acts as an essential factor in mesenchymal stem cell differentiation through the regulation of the dynamics of the Wnt/beta-catenin pathway. J Cell Biochem 116, 2344-2353.

Bertacchini, J., Beretti, F., Cenni, V., Guida, M., Gibellini, F., Mediani, L., Marin, O., Maraldi, N.M., de Pol, A., Lattanzi, G., Cocco, L., Marmiroli, S., 2013. The protein kinase Akt/PKB regulates both prelamin A degradation and $L m n a$ gene expression. FASEB J 27, 2145-2155.

889 Bertrand, A.T., Ziaei, S., Ehret, C., Duchemin, H., Mamchaoui, K., Bigot, A., Mayer, M., 890 Quijano-Roy, S., Desguerre, I., Laine, J., Ben Yaou, R., Bonne, G., Coirault, C., 2014.

891 Cellular microenvironments reveal defective mechanosensing responses and elevated 892 YAP signaling in LMNA-mutated muscle precursors. J Cell Sci 127, 2873-2884.

893 Blanco, R., Munoz, P., Flores, J.M., Klatt, P., Blasco, M.A., 2007. Telomerase abrogation 894 dramatically accelerates TRF2-induced epithelial carcinogenesis. Genes Dev 21, 206-

895220. 
896

897

898

899

900

901

902

903

904

905

906

907

908

909

910

911

912

913

914

915

916

917

918

919

920

921

922

923

924

925

926

927

928

929

930

931

932

933

934

935

936

937

938

939

940

941

942

943

944

945

946
Boguslavsky, R.L., Stewart, C.L., Worman, H.J., 2006. Nuclear lamin A inhibits adipocyte differentiation: implications for Dunnigan-type familial partial lipodystrophy. Hum Mol Genet 15, 653-663.

Boyd, J., Pienta, K.J., Getzenberg, R.H., Coffey, D.S., Barrett, J.C., 1991. Preneoplastic alterations in nuclear morphology that accompany loss of tumor suppressor phenotype. $\mathrm{J}$ Natl Cancer Inst 83, 862-866.

Broers, J.L., Machiels, B.M., Kuijpers, H.J., Smedts, F., van den Kieboom, R., Raymond, Y., Ramaekers, F.C., 1997. A- and B-type lamins are differentially expressed in normal human tissues. Histochem Cell Biol 107, 505-517.

Broers, J.L., Peeters, E.A., Kuijpers, H.J., Endert, J., Bouten, C.V., Oomens, C.W., Baaijens, F.P., Ramaekers, F.C., 2004. Decreased mechanical stiffness in LMNA-/- cells is caused by defective nucleo-cytoskeletal integrity: implications for the development of laminopathies. Hum Mol Genet 13, 2567-2580.

Bronshtein, I., Kepten, E., Kanter, I., Berezin, S., Lindner, M., Redwood, A.B., Mai, S., Gonzalo, S., Foisner, R., Shav-Tal, Y., Garini, Y., 2015. Loss of lamin A function increases chromatin dynamics in the nuclear interior. Nat Commun 6, 8044.

Bru, T., Clarke, C., McGrew, M.J., Sang, H.M., Wilmut, I., Blow, J.J., 2008. Rapid induction of pluripotency genes after exposure of human somatic cells to mouse ES cell extracts. Exp Cell Res 314, 2634-2642.

Bussolati, G., Maletta, F., Asioli, S., Annaratone, L., Sapino, A., Marchio, C., 2014. "To be or not to be in a good shape": diagnostic and clinical value of nuclear shape irregularities in thyroid and breast cancer. Adv Exp Med Biol 773, 101-121.

Bussolati, G., Marchio, C., Gaetano, L., Lupo, R., Sapino, A., 2008. Pleomorphism of the nuclear envelope in breast cancer: a new approach to an old problem. J Cell Mol Med 12, 209-218.

Bustin, M., Misteli, T., 2016. Nongenetic functions of the genome. Science 352, aad6933.

Buxboim, A., Swift, J., Irianto, J., Spinler, K.R., Dingal, P.C., Athirasala, A., Kao, Y.R., Cho, S., Harada, T., Shin, J.W., Discher, D.E., 2014. Matrix elasticity regulates laminA,C phosphorylation and turnover with feedback to actomyosin. Curr Biol 24, 1909-1917. Candelario, J., Sudhakar, S., Navarro, S., Reddy, S., Comai, L., 2008. Perturbation of wild-type lamin A metabolism results in a progeroid phenotype. Aging Cell 7, 355-367. Cekaite, L., Rantala, J.K., Bruun, J., Guriby, M., Agesen, T.H., Danielsen, S.A., Lind, G.E., Nesbakken, A., Kallioniemi, O., Lothe, R.A., Skotheim, R.I., 2012. MiR-9, -31, and 182 deregulation promote proliferation and tumor cell survival in colon cancer. Neoplasia $14,868-879$.

Cenni, V., Bertacchini, J., Beretti, F., Lattanzi, G., Bavelloni, A., Riccio, M., Ruzzene, M., Marin, O., Arrigoni, G., Parnaik, V., Wehnert, M., Maraldi, N.M., de Pol, A., Cocco, L., Marmiroli, S., 2008. Lamin A Ser404 is a nuclear target of Akt phosphorylation in C2C12 cells. J Proteome Res 7, 4727-4735.

Cerami, E., Gao, J., Dogrusoz, U., Gross, B.E., Sumer, S.O., Aksoy, B.A., Jacobsen, A., Byrne, C.J., Heuer, M.L., Larsson, E., Antipin, Y., Reva, B., Goldberg, A.P., Sander, C., Schultz, N., 2012. The cBio cancer genomics portal: an open platform for exploring multidimensional cancer genomics data. Cancer Discov 2, 401-404.

Chaudhuri, O., Koshy, S.T., Branco da Cunha, C., Shin, J.W., Verbeke, C.S., Allison, K.H., Mooney, D.J., 2014. Extracellular matrix stiffness and composition jointly regulate the induction of malignant phenotypes in mammary epithelium. Nat Mater 13, 970-978. Chiarle, R., Zhang, Y., Frock, R.L., Lewis, S.M., Molinie, B., Ho, Y.J., Myers, D.R., Choi, V.W., Compagno, M., Malkin, D.J., Neuberg, D., Monti, S., Giallourakis, C.C., Gostissa, M., Alt, F.W., 2011. Genome-wide translocation sequencing reveals mechanisms of chromosome breaks and rearrangements in B cells. Cell 147, 107-119. 

cancer connections. Nat Rev Cancer 12, 196-209.

Clevers, H., Nusse, R., 2012. Wnt/beta-catenin signaling and disease. Cell 149, 11921205.

Collas, P., 1999. Sequential PKC- and Cdc2-mediated phosphorylation events elicit zebrafish nuclear envelope disassembly. J Cell Sci 112 ( Pt 6), 977-987.

Constantinescu, D., Gray, H.L., Sammak, P.J., Schatten, G.P., Csoka, A.B., 2006. Lamin $\mathrm{A} / \mathrm{C}$ expression is a marker of mouse and human embryonic stem cell differentiation. Stem Cells 24, 177-185.

Coussens, L.M., Fingleton, B., Matrisian, L.M., 2002. Matrix metalloproteinase inhibitors and cancer: trials and tribulations. Science 295, 2387-2392.

Davidson, P.M., Denais, C., Bakshi, M.C., Lammerding, J., 2014. Nuclear deformability constitutes a rate-limiting step during cell migration in 3-D environments. Cell Mol Bioeng 7, 293-306.

961 de Las Heras, J.I., Schirmer, E.C., 2014. The nuclear envelope and cancer: a diagnostic 962 perspective and historical overview. Adv Exp Med Biol 773, 5-26.

963 De Vos, W.H., Houben, F., Kamps, M., Malhas, A., Verheyen, F., Cox, J., Manders, 964 E.M., Verstraeten, V.L., van Steensel, M.A., Marcelis, C.L., van den Wijngaard, A., Vaux, 965 D.J., Ramaekers, F.C., Broers, J.L., 2011. Repetitive disruptions of the nuclear envelope 966 invoke temporary loss of cellular compartmentalization in laminopathies. Hum Mol Genet 967 20, 4175-4186.

968 Denais, C., Lammerding, J., 2014. Nuclear mechanics in cancer. Adv Exp Med Biol 773, 969 435-470.

970

971

972

973

974

975

976

977

978

979

980

981

982

983

984

985

986

987

988

989

990

991

992

993

994

995

996

Denais, C.M., Gilbert, R.M., Isermann, P., McGregor, A.L., Te Lindert, M., Weigelin, B., Davidson, P.M., Friedl, P., Wolf, K., Lammerding, J., 2016. Nuclear envelope rupture and repair during cancer cell migration. Science 352, 353-358.

Dhillon, A.S., Hagan, S., Rath, O., Kolch, W., 2007. MAP kinase signalling pathways in cancer. Oncogene 26, 3279-3290.

Dilly, A.K., Ekambaram, P., Guo, Y., Cai, Y., Tucker, S.C., Fridman, R., Kandouz, M., Honn, K.V., 2013. Platelet-type 12-lipoxygenase induces MMP9 expression and cellular invasion via activation of PI3K/Akt/NF-kappaB. Int J Cancer 133, 1784-1791.

Doerschuk, C.M., Beyers, N., Coxson, H.O., Wiggs, B., Hogg, J.C., 1993. Comparison of neutrophil and capillary diameters and their relation to neutrophil sequestration in the lung. J Appl Physiol (1985) 74, 3040-3045.

Dorner, D., Vlcek, S., Foeger, N., Gajewski, A., Makolm, C., Gotzmann, J., Hutchison, C.J., Foisner, R., 2006. Lamina-associated polypeptide 2 alpha regulates cell cycle progression and differentiation via the retinoblastoma-E2F pathway. J Cell Biol 173, 8393.

Emerson, L.J., Holt, M.R., Wheeler, M.A., Wehnert, M., Parsons, M., Ellis, J.A., 2009. Defects in cell spreading and ERK1/2 activation in fibroblasts with lamin A/C mutations. Biochim Biophys Acta 1792, 810-821.

Engelman, J.A., 2009. Targeting PI3K signalling in cancer: opportunities, challenges and limitations. Nat Rev Cancer 9, 550-562.

Espada, J., Varela, I., Flores, I., Ugalde, A.P., Cadinanos, J., Pendas, A.M., Stewart, C.L., Tryggvason, K., Blasco, M.A., Freije, J.M., Lopez-Otin, C., 2008. Nuclear envelope defects cause stem cell dysfunction in premature-aging mice. J Cell Biol 181, 27-35.

Esteller, M., 2008. Epigenetics in cancer. N Engl J Med 358, 1148-1159.

Evangelisti, C., Bernasconi, P., Cavalcante, P., Cappelletti, C., D'Apice, M.R., Sbraccia, P., Novelli, G., Prencipe, S., Lemma, S., Baldini, N., Avnet, S., Squarzoni, S., Martelli, A.M., Lattanzi, G., 2015. Modulation of TGFbeta 2 levels by lamin A in U2-OS 
osteoblast-like cells: understanding the osteolytic process triggered by altered lamins. Oncotarget 6, 7424-7437. Fenner, J., Stacer, A.C., Winterroth, F., Johnson, T.D., Luker, K.E., Luker, G.D., 2014. Macroscopic stiffness of breast tumors predicts metastasis. Sci Rep 4, 5512.

1001

1002

1003

1004

1005 Ferraro, A., Eufemi, M., Cervoni, L., Marinetti, R., Turano, C., 1989. Glycosylated forms of nuclear lamins. FEBS Lett 257, 241-246.

1008 Ferrera, D., Canale, C., Marotta, R., Mazzaro, N., Gritti, M., Mazzanti, M., Capellari, S., Cortelli, P., Gasparini, L., 2014. Lamin B1 overexpression increases nuclear rigidity in autosomal dominant leukodystrophy fibroblasts. FASEB J 28, 3906-3918. Finlan, L.E., Sproul, D., Thomson, I., Boyle, S., Kerr, E., Perry, P., Ylstra, B., Chubb, J.R., Bickmore, W.A., 2008. Recruitment to the nuclear periphery can alter expression of genes in human cells. PLoS Genet 4, e1000039.

1011 Fischer, A.H., 2014. The diagnostic pathology of the nuclear envelope in human cancers. Adv Exp Med Biol 773, 49-75.

1012 Fischer, A.H., Bond, J.A., Taysavang, P., Battles, O.E., Wynford-Thomas, D., 1998.

1013 Papillary thyroid carcinoma oncogene (RET/PTC) alters the nuclear envelope and chromatin structure. Am J Pathol 153, 1443-1450.

1014

1015

1016 Frock, R.L., Kudlow, B.A., Evans, A.M., Jameson, S.A., Hauschka, S.D., Kennedy, B.K., 2006. Lamin $A / C$ and emerin are critical for skeletal muscle satellite cell differentiation.

1017

1018 Genes Dev 20, 486-500.

1019

1020

1021

1022

1023

1024

1025

1026

1027

1028

1029

1030

1031

1032

1033

1034

1035

1036

1037

1038

1039

1040

1041

1042

1043

1044 Fruman, D.A., Rommel, C., 2014. PI3K and cancer: lessons, challenges and opportunities. Nat Rev Drug Discov 13, 140-156.

Galiova, G., Bartova, E., Raska, I., Krejci, J., Kozubek, S., 2008. Chromatin changes induced by lamin $A / C$ deficiency and the histone deacetylase inhibitor trichostatin $A$. Eur J Cell Biol 87, 291-303.

Gao, J., Aksoy, B.A., Dogrusoz, U., Dresdner, G., Gross, B., Sumer, S.O., Sun, Y., Jacobsen, A., Sinha, R., Larsson, E., Cerami, E., Sander, C., Schultz, N., 2013. Integrative analysis of complex cancer genomics and clinical profiles using the cBioPortal. Sci Signal 6, pl1.

Giacinti, C., Giordano, A., 2006. RB and cell cycle progression. Oncogene 25, 52205227.

Gibbs-Seymour, I., Markiewicz, E., Bekker-Jensen, S., Mailand, N., Hutchison, C.J., 2015. Lamin A/C-dependent interaction with 53BP1 promotes cellular responses to DNA damage. Aging Cell 14, 162-169.

Gomis, R.R., Alarcon, C., He, W., Wang, Q., Seoane, J., Lash, A., Massague, J., 2006. A FoxO-Smad synexpression group in human keratinocytes. Proc Natl Acad Sci U S A 103, 12747-12752.

Gong, G., Chen, P., Li, L., Tan, H., Zhou, J., Zhou, Y., Yang, X., Wu, X., 2015. Loss of lamin $A$ but not lamin $C$ expression in epithelial ovarian cancer cells is associated with metastasis and poor prognosis. Pathol Res Pract 211, 175-182.

Gonzalez, J.M., Navarro-Puche, A., Casar, B., Crespo, P., Andres, V., 2008. Fast regulation of AP-1 activity through interaction of lamin A/C, ERK1/2, and c-Fos at the nuclear envelope. J Cell Biol 183, 653-666.

Gonzalez-Suarez, I., Redwood, A.B., Perkins, S.M., Vermolen, B., Lichtensztejin, D., Grotsky, D.A., Morgado-Palacin, L., Gapud, E.J., Sleckman, B.P., Sullivan, T., Sage, J., Stewart, C.L., Mai, S., Gonzalo, S., 2009. Novel roles for A-type lamins in telomere biology and the DNA damage response pathway. EMBO J 28, 2414-2427.

Gonzalo, S., 2014. DNA damage and lamins. Adv Exp Med Biol 773, 377-399.

1047

Gruenbaum, Y., Foisner, R., 2015. Lamins: nuclear intermediate filament proteins with fundamental functions in nuclear mechanics and genome regulation. Annu Rev Biochem 84, 131-164. 
1048 Gruenbaum, Y., Medalia, O., 2015. Lamins: the structure and protein complexes. Curr 1049 Opin Cell Biol 32, 7-12.

1050 Guarda, A., Bolognese, F., Bonapace, I.M., Badaracco, G., 2009. Interaction between

1051

1052

1053

1054

1055

1056

1057

1058

1059 the inner nuclear membrane lamin $B$ receptor and the heterochromatic methyl binding protein, MeCP2. Exp Cell Res 315, 1895-1903.

Guelen, L., Pagie, L., Brasset, E., Meuleman, W., Faza, M.B., Talhout, W., Eussen, B.H., de Klein, A., Wessels, L., de Laat, W., van Steensel, B., 2008. Domain organization of human chromosomes revealed by mapping of nuclear lamina interactions. Nature 453, 948-951.

1060 Guo, D., Bell, E.H., Mischel, P., Chakravarti, A., 2014. Targeting SREBP-1-driven lipid

1061 metabolism to treat cancer. Curr Pharm Des 20, 2619-2626.

1062 Hanahan, D., Weinberg, R.A., 2011. Hallmarks of cancer: the next generation. Cell 144, 1063 646-674.

1064 Harada, T., Swift, J., Irianto, J., Shin, J.W., Spinler, K.R., Athirasala, A., Diegmiller, R., 1065 Dingal, P.C., Ivanovska, I.L., Discher, D.E., 2014. Nuclear lamin stiffness is a barrier to 1066 3D migration, but softness can limit survival. J Cell Biol 204, 669-682.

1067 Harley, C.B., 2008. Telomerase and cancer therapeutics. Nat Rev Cancer 8, 167-179.

1068 Hatch, E.M., Fischer, A.H., Deerinck, T.J., Hetzer, M.W., 2013. Catastrophic nuclear

1069

1070

1071

1072

1073

1074

1075

1076

1077

1078

1079

1080

1081

1082

1083

1084

1085

1086

1087

1088

1089

1090

1091

1092

1093

1094

1095

1096

1097 envelope collapse in cancer cell micronuclei. Cell 154, 47-60.

Haughian, J.M., Reno, E.M., Thorne, A.M., Bradford, A.P., 2009. Protein kinase C alphadependent signaling mediates endometrial cancer cell growth and tumorigenesis. Int $\mathrm{J}$ Cancer 125, 2556-2564.

Hernandez, L., Roux, K.J., Wong, E.S., Mounkes, L.C., Mutalif, R., Navasankari, R., Rai, B., Cool, S., Jeong, J.W., Wang, H., Lee, H.S., Kozlov, S., Grunert, M., Keeble, T., Jones, C.M., Meta, M.D., Young, S.G., Daar, I.O., Burke, B., Perantoni, A.O., Stewart, C.L., 2010. Functional coupling between the extracellular matrix and nuclear lamina by Wnt signaling in progeria. Dev Cell 19, 413-425.

Hetzer, M.W., 2010. The nuclear envelope. Cold Spring Harb Perspect Biol 2, a000539. Ho, C.Y., Jaalouk, D.E., Vartiainen, M.K., Lammerding, J., 2013. Lamin A/C and emerin regulate MKL1-SRF activity by modulating actin dynamics. Nature 497, 507-511. Ho, C.Y., Lammerding, J., 2012. Lamins at a glance. J Cell Sci 125, 2087-2093. Holaska, J.M., Kowalski, A.K., Wilson, K.L., 2004. Emerin caps the pointed end of actin filaments: evidence for an actin cortical network at the nuclear inner membrane. PLoS Biol 2, E231.

Honn, K.V., Tang, D.G., Gao, X., Butovich, I.A., Liu, B., Timar, J., Hagmann, W., 1994. 12-lipoxygenases and 12(S)-HETE: role in cancer metastasis. Cancer Metastasis Rev 13, 365-396.

Houben, F., Willems, C.H., Declercq, I.L., Hochstenbach, K., Kamps, M.A., Snoeckx, L.H., Ramaekers, F.C., Broers, J.L., 2009. Disturbed nuclear orientation and cellular migration in A-type lamin deficient cells. Biochim Biophys Acta 1793, 312-324. Hutchison, C.J., 2011. The role of DNA damage in laminopathy progeroid syndromes. Biochem Soc Trans 39, 1715-1718.

Ihalainen, T.O., Aires, L., Herzog, F.A., Schwartlander, R., Moeller, J., Vogel, V., 2015. Differential basal-to-apical accessibility of lamin A/C epitopes in the nuclear lamina regulated by changes in cytoskeletal tension. Nat Mater 14, 1252-1261.

Irianto, J., Pfeifer, C.R., Ivanovska, I.L., Swift, J., Discher, D., 2016. Nuclear lamins in cancer. Cellular and Molecular Bioengineering 9, 258-267. 

health and disease. Curr Biol 23, R1113-1121. Ivorra, C., Kubicek, M., Gonzalez, J.M., Sanz-Gonzalez, S.M., Alvarez-Barrientos, A., O'Connor, J.E., Burke, B., Andres, V., 2006. A mechanism of AP-1 suppression through interaction of C-Fos with lamin A/C. Genes Dev 20, 307-320.

Johnson, B.R., Nitta, R.T., Frock, R.L., Mounkes, L., Barbie, D.A., Stewart, C.L., Harlow, E., Kennedy, B.K., 2004. A-type lamins regulate retinoblastoma protein function by promoting subnuclear localization and preventing proteasomal degradation. Proc Natl Acad Sci U S A 101, 9677-9682.

1107 Johnson, J., Thijssen, B., McDermott, U., Garnett, M., Wessels, L.F., Bernards, R., 2016. Targeting the RB-E2F pathway in breast cancer. Oncogene doi: 10.1038/onc.2016.32. Jung, H.J., Coffinier, C., Choe, Y., Beigneux, A.P., Davies, B.S., Yang, S.H., Barnes, R.H., 2nd, Hong, J., Sun, T., Pleasure, S.J., Young, S.G., Fong, L.G., 2012. Regulation of prelamin A but not lamin C by miR-9, a brain-specific microRNA. Proc Natl Acad Sci U S A 109, E423-431.

1113 Kerjaschki, D., Bago-Horvath, Z., Rudas, M., Sexl, V., Schneckenleithner, C., Wolbank, 1114 S., Bartel, G., Krieger, S., Kalt, R., Hantusch, B., Keller, T., Nagy-Bojarszky, K., Huttary, N., Raab, I., Lackner, K., Krautgasser, K., Schachner, H., Kaserer, K., Rezar, S., Madlener, S., Vonach, C., Davidovits, A., Nosaka, H., Hammerle, M., Viola, K., Dolznig, H., Schreiber, M., Nader, A., Mikulits, W., Gnant, M., Hirakawa, S., Detmar, M., Alitalo, K., Nijman, S., Offner, F., Maier, T.J., Steinhilber, D., Krupitza, G., 2011. Lipoxygenase mediates invasion of intrametastatic lymphatic vessels and propagates lymph node metastasis of human mammary carcinoma xenografts in mouse. J Clin Invest 121, 20002012.

Kircher, P., Hermanns, C., Nossek, M., Drexler, M.K., Grosse, R., Fischer, M., Sarikas, A., Penkava, J., Lewis, T., Prywes, R., Gudermann, T., Muehlich, S., 2015. Filamin A interacts with the coactivator MKL1 to promote the activity of the transcription factor SRF and cell migration. Sci Signal 8, ra112.

Klampfl, T., Bogner, E., Bednar, W., Mager, L., Massudom, D., Kalny, I., Heinzle, C., Berger, W., Stattner, S., Karner, J., Klimpfinger, M., Furstenberger, G., Krieg, P., Marian, B., 2012. Up-regulation of 12(S)-lipoxygenase induces a migratory phenotype in colorectal cancer cells. Exp Cell Res 318, 768-778.

Kochin, V., Shimi, T., Torvaldson, E., Adam, S.A., Goldman, A., Pack, C.G., MeloCardenas, J., Imanishi, S.Y., Goldman, R.D., Eriksson, J.E., 2014. Interphase phosphorylation of lamin A. J Cell Sci 127, 2683-2696.

Kong, L., Schafer, G., Bu, H., Zhang, Y., Zhang, Y., Klocker, H., 2012. Lamin A/C protein is overexpressed in tissue-invading prostate cancer and promotes prostate cancer cell growth, migration and invasion through the PI3K/AKT/PTEN pathway. Carcinogenesis 33, 751-759.

Krishnan, V., Chow, M.Z., Wang, Z., Zhang, L., Liu, B., Liu, X., Zhou, Z., 2011. Histone $\mathrm{H} 4$ lysine 16 hypoacetylation is associated with defective DNA repair and premature senescence in Zmpste24-deficient mice. Proc Natl Acad Sci U S A 108, 12325-12330. Lammerding, J., Fong, L.G., Ji, J.Y., Reue, K., Stewart, C.L., Young, S.G., Lee, R.T., 2006. Lamins A and C but not lamin B1 regulate nuclear mechanics. J Biol Chem 281, 25768-25780.

Lammerding, J., Hsiao, J., Schulze, P.C., Kozlov, S., Stewart, C.L., Lee, R.T., 2005. Abnormal nuclear shape and impaired mechanotransduction in emerin-deficient cells. J Cell Biol 170, 781-791.

Lammerding, J., Schulze, P.C., Takahashi, T., Kozlov, S., Sullivan, T., Kamm, R.D., mechanics and mechanotransduction. J Clin Invest 113, 370-378. 

inhibition of NAT10 corrects defects of laminopathic cells. Science 344, 527-532. Lee, D.C., Welton, K.L., Smith, E.D., Kennedy, B.K., 2009. A-type nuclear lamins act as transcriptional repressors when targeted to promoters. Exp Cell Res 315, 996-1007.

1154

1155

1156

1157

1158

1159 Lee, J.S., Hale, C.M., Panorchan, P., Khatau, S.B., George, J.P., Tseng, Y., Stewart, C.L., Hodzic, D., Wirtz, D., 2007. Nuclear lamin A/C deficiency induces defects in cell mechanics, polarization, and migration. Biophys J 93, 2542-2552.

Lee, W.C., Shi, H., Poon, Z., Nyan, L.M., Kaushik, T., Shivashankar, G.V., Chan, J.K., Lim, C.T., Han, J., Van Vliet, K.J., 2014. Multivariate biophysical markers predictive of mesenchymal stromal cell multipotency. Proc Natl Acad Sci U S A 111, E4409-4418. Lee, W.S., Jung, J.J., Jeung, H.C., Noh, S.W., Oh, B.K., Kim, K.Y., Kim, T.S., Chung, H.C., Roh, J.K., Rha, S.Y., 2012. Methylation status of lamin A/C in gastric cancer cell lines. Hepatogastroenterology 59, 1313-1318.

1164 Leight, J.L., Wozniak, M.A., Chen, S., Lynch, M.L., Chen, C.S., 2012. Matrix rigidity regulates a switch between TGF-beta1-induced apoptosis and epithelial-mesenchymal transition. Mol Biol Cell 23, 781-791.

1165 
Ma, L., Young, J., Prabhala, H., Pan, E., Mestdagh, P., Muth, D., Teruya-Feldstein, J., Reinhardt, F., Onder, T.T., Valastyan, S., Westermann, F., Speleman, F., Vandesompele, J., Weinberg, R.A., 2010. miR-9, a MYC/MYCN-activated microRNA, regulates E-cadherin and cancer metastasis. Nat Cell Biol 12, 247-256. Makhija, E., Jokhun, D.S., Shivashankar, G.V., 2016. Nuclear deformability and telomere dynamics are regulated by cell geometric constraints. Proc Natl Acad Sci U S A 113, E32-40.

Mani, S.A., Guo, W., Liao, M.J., Eaton, E.N., Ayyanan, A., Zhou, A.Y., Brooks, M., Reinhard, F., Zhang, C.C., Shipitsin, M., Campbell, L.L., Polyak, K., Brisken, C., Yang, J., Weinberg, R.A., 2008. The epithelial-mesenchymal transition generates cells with properties of stem cells. Cell 133, 704-715.

Markiewicz, E., Dechat, T., Foisner, R., Quinlan, R.A., Hutchison, C.J., 2002. Lamin A/C binding protein LAP2alpha is required for nuclear anchorage of retinoblastoma protein. Mol Biol Cell 13, 4401-4413.

Markiewicz, E., Tilgner, K., Barker, N., van de Wetering, M., Clevers, H., Dorobek, M., Hausmanowa-Petrusewicz, I., Ramaekers, F.C., Broers, J.L., Blankesteijn, W.M., Salpingidou, G., Wilson, R.G., Ellis, J.A., Hutchison, C.J., 2006. The inner nuclear membrane protein emerin regulates beta-catenin activity by restricting its accumulation in the nucleus. EMBO J 25, 3275-3285.

Martelli, A.M., Bortul, R., Tabellini, G., Faenza, I., Cappellini, A., Bareggi, R., Manzoli, L., Cocco, L., 2002. Molecular characterization of protein kinase C-alpha binding to lamin A. $\mathrm{J}$ Cell Biochem 86, 320-330.

Matsumoto, A., Hieda, M., Yokoyama, Y., Nishioka, Y., Yoshidome, K., Tsujimoto, M., Matsuura, N., 2015. Global loss of a nuclear lamina component, lamin A/C, and LINC complex components SUN1, SUN2, and nesprin-2 in breast cancer. Cancer Med 4, 1547-1557.

Mauro, A., Ciccarelli, C., De Cesaris, P., Scoglio, A., Bouche, M., Molinaro, M., Aquino, A., Zani, B.M., 2002. PKCalpha-mediated ERK, JNK and p38 activation regulates the myogenic program in human rhabdomyosarcoma cells. J Cell Sci 115, 3587-3599. McGregor, A.L., Hsia, C.R., Lammerding, J., 2016. Squish and squeeze-the nucleus as a physical barrier during migration in confined environments. Curr Opin Cell Biol 40, $32-$ 40. Medema, J.P., 2013. Cancer stem cells: the challenges ahead. Nat Cell Biol 15, 338344.

Medjkane, S., Perez-Sanchez, C., Gaggioli, C., Sahai, E., Treisman, R., 2009. Myocardin-related transcription factors and SRF are required for cytoskeletal dynamics and experimental metastasis. Nat Cell Biol 11, 257-268.

Melcon, G., Kozlov, S., Cutler, D.A., Sullivan, T., Hernandez, L., Zhao, P., Mitchell, S., Nader, G., Bakay, M., Rottman, J.N., Hoffman, E.P., Stewart, C.L., 2006. Loss of emerin at the nuclear envelope disrupts the Rb1/E2F and MyoD pathways during muscle regeneration. Hum Mol Genet 15, 637-651.

Mitchell, M.J., Denais, C., Chan, M.F., Wang, Z., Lammerding, J., King, M.R., 2015. Lamin $A / C$ deficiency reduces circulating tumor cell resistance to fluid shear stress. Am J Physiol Cell Physiol 309, C736-746.

Morita, T., Mayanagi, T., Sobue, K., 2007. Dual roles of myocardin-related transcription factors in epithelial mesenchymal transition via slug induction and actin remodeling. J Cell Biol 179, 1027-1042.

Moroishi, T., Hansen, C.G., Guan, K.L., 2015. The emerging roles of YAP and TAZ in cancer. Nat Rev Cancer 15, 73-79.

Moses, H., Barcellos-Hoff, M.H., 2011. TGF-beta biology in mammary development and breast cancer. Cold Spring Harb Perspect Biol 3, a003277. 
Muchir, A., Pavlidis, P., Decostre, V., Herron, A.J., Arimura, T., Bonne, G., Worman, H.J., 2007. Activation of MAPK pathways links LMNA mutations to cardiomyopathy in Emery-Dreifuss muscular dystrophy. J Clin Invest 117, 1282-1293. Muchir, A., Reilly, S.A., Wu, W., Iwata, S., Homma, S., Bonne, G., Worman, H.J., 2012a. Treatment with selumetinib preserves cardiac function and improves survival in cardiomyopathy caused by mutation in the lamin A/C gene. Cardiovasc Res 93, 311319.

Muchir, A., Wu, W., Choi, J.C., Iwata, S., Morrow, J., Homma, S., Worman, H.J., 2012b. Abnormal p38alpha mitogen-activated protein kinase signaling in dilated cardiomyopathy caused by lamin A/C gene mutation. Hum Mol Genet 21, 4325-4333.

Muchir, A., Wu, W., Worman, H.J., 2009. Reduced expression of A-type lamins and emerin activates extracellular signal-regulated kinase in cultured cells. Biochim Biophys Acta 1792, 75-81.

Muller, P.A., Vousden, K.H., 2014. Mutant p53 in cancer: new functions and therapeutic opportunities. Cancer Cell 25, 304-317. Myant, K., Qiao, X., Halonen, T., Come, C., Laine, A., Janghorban, M., Partanen, J.I., Cassidy, J., Ogg, E.L., Cammareri, P., Laitera, T., Okkeri, J., Klefstrom, J., Sears, R.C., Sansom, O.J., Westermarck, J., 2015. Serine 62-Phosphorylated MYC Associates with Nuclear Lamins and Its Regulation by CIP2A Is Essential for Regenerative Proliferation. Cell Rep 12, 1019-1031.

Naeem, A.S., Zhu, Y., Di, W.L., Marmiroli, S., O'Shaughnessy, R.F., 2015. AKT1mediated Lamin $A / C$ degradation is required for nuclear degradation and normal epidermal terminal differentiation. Cell Death Differ 22, 2123-2132.

Nardella, M., Guglielmi, L., Musa, C., Iannetti, I., Maresca, G., Amendola, D., Porru, M., Carico, E., Sessa, G., Camerlingo, R., Dominici, C., Megiorni, F., Milan, M., Bearzi, C., Rizzi, R., Pirozzi, G., Leonetti, C., Bucci, B., Mercanti, D., Felsani, A., D'Agnano, I., 2015. Down-regulation of the Lamin $A / C$ in neuroblastoma triggers the expansion of tumor initiating cells. Oncotarget 6, 32821-32840.

Negrini, S., Gorgoulis, V.G., Halazonetis, T.D., 2010. Genomic instability--an evolving hallmark of cancer. Nat Rev Mol Cell Biol 11, 220-228.

Neumann, S., Schneider, M., Daugherty, R.L., Gottardi, C.J., Eming, S.A., Beijer, A., Noegel, A.A., Karakesisoglou, I., 2010. Nesprin-2 interacts with \{alpha\}-catenin and regulates Wnt signaling at the nuclear envelope. J Biol Chem 285, 34932-34938. Nitta, R.T., Jameson, S.A., Kudlow, B.A., Conlan, L.A., Kennedy, B.K., 2006. Stabilization of the retinoblastoma protein by A-type nuclear lamins is required for INK4A-mediated cell cycle arrest. Mol Cell Biol 26, 5360-5372.

Okumura, K., Hosoe, Y., Nakajima, N., 2004. c-Jun and Sp1 family are critical for retinoic acid induction of the lamin A/C retinoic acid-responsive element. Biochem Biophys Res Commun 320, 487-492.

Olson, E.N., Nordheim, A., 2010. Linking actin dynamics and gene transcription to drive cellular motile functions. Nat Rev Mol Cell Biol 11, 353-365.

Pajerowski, J.D., Dahl, K.N., Zhong, F.L., Sammak, P.J., Discher, D.E., 2007. Physical plasticity of the nucleus in stem cell differentiation. Proc Natl Acad Sci U S A 104, 1561915624.

Papageorgis, P., 2015. TGFbeta Signaling in Tumor Initiation, Epithelial-to-Mesenchymal Transition, and Metastasis. J Oncol 2015, 587193.

Parada, L.A., McQueen, P.G., Misteli, T., 2004. Tissue-specific spatial organization of genomes. Genome Biol 5, R44.

Paszek, M.J., Zahir, N., Johnson, K.R., Lakins, J.N., Rozenberg, G.I., Gefen, A., Reinhart-King, C.A., Margulies, S.S., Dembo, M., Boettiger, D., Hammer, D.A., Weaver, 

254.

Pegoraro, G., Kubben, N., Wickert, U., Gohler, H., Hoffmann, K., Misteli, T., 2009. Ageing-related chromatin defects through loss of the NURD complex. Nat Cell Biol 11, 1261-1267.

Pekovic, V., Gibbs-Seymour, I., Markiewicz, E., Alzoghaibi, F., Benham, A.M., Edwards, R., Wenhert, M., von Zglinicki, T., Hutchison, C.J., 2011. Conserved cysteine residues in the mammalian lamin A tail are essential for cellular responses to ROS generation. Aging Cell 10, 1067-1079.

Pekovic, V., Harborth, J., Broers, J.L., Ramaekers, F.C., van Engelen, B., Lammens, M., von Zglinicki, T., Foisner, R., Hutchison, C., Markiewicz, E., 2007. Nucleoplasmic LAP2alpha-lamin A complexes are required to maintain a proliferative state in human fibroblasts. J Cell Biol 176, 163-172.

1314 Peric-Hupkes, D., Meuleman, W., Pagie, L., Bruggeman, S.W., Solovei, I., Brugman, W., Graf, S., Flicek, P., Kerkhoven, R.M., van Lohuizen, M., Reinders, M., Wessels, L., van Steensel, B., 2010. Molecular maps of the reorganization of genome-nuclear lamina interactions during differentiation. Mol Cell 38, 603-613.

Perkins, N.D., 2004. NF-kappaB: tumor promoter or suppressor? Trends Cell Biol 14, 64-69.

Peter, M., Nakagawa, J., Doree, M., Labbe, J.C., Nigg, E.A., 1990. In vitro disassembly of the nuclear lamina and $\mathrm{M}$ phase-specific phosphorylation of lamins by cdc2 kinase. Cell 61, 591-602.

Pickup, M.W., Mouw, J.K., Weaver, V.M., 2014. The extracellular matrix modulates the hallmarks of cancer. EMBO Rep 15, 1243-1253.

Pipes, G.C., Creemers, E.E., Olson, E.N., 2006. The myocardin family of transcriptional coactivators: versatile regulators of cell growth, migration, and myogenesis. Genes Dev 20, 1545-1556.

Plodinec, M., Loparic, M., Monnier, C.A., Obermann, E.C., Zanetti-Dallenbach, R., Oertle, P., Hyotyla, J.T., Aebi, U., Bentires-Alj, M., Lim, R.Y., Schoenenberger, C.A., 2012. The nanomechanical signature of breast cancer. Nat Nanotechnol 7, 757-765. Polager, S., Ginsberg, D., 2009. p53 and E2f: partners in life and death. Nat Rev Cancer 9, 738-748.

Pombo, A., Dillon, N., 2015. Three-dimensional genome architecture: players and mechanisms. Nat Rev Mol Cell Biol 16, 245-257.

Provenzano, P.P., Eliceiri, K.W., Campbell, J.M., Inman, D.R., White, J.G., Keely, P.J., 2006. Collagen reorganization at the tumor-stromal interface facilitates local invasion. BMC Med 4, 38.

Qi, Y.X., Jiang, J., Jiang, X.H., Wang, X.D., Ji, S.Y., Han, Y., Long, D.K., Shen, B.R., Yan, Z.Q., Chien, S., Jiang, Z.L., 2011. PDGF-BB and TGF-\{beta\}1 on cross-talk between endothelial and smooth muscle cells in vascular remodeling induced by low shear stress. Proc Natl Acad Sci U S A 108, 1908-1913.

Quail, D.F., Joyce, J.A., 2013. Microenvironmental regulation of tumor progression and metastasis. Nat Med 19, 1423-1437.

Raab, M., Gentili, M., de Belly, H., Thiam, H.R., Vargas, P., Jimenez, A.J., Lautenschlaeger, F., Voituriez, R., Lennon-Dumenil, A.M., Manel, N., Piel, M., 2016. ESCRT III repairs nuclear envelope ruptures during cell migration to limit DNA damage and cell death. Science 352, 359-362.

Ramos, F.J., Chen, S.C., Garelick, M.G., Dai, D.F., Liao, C.Y., Schreiber, K.H., MacKay, V.L., An, E.H., Strong, R., Ladiges, W.C., Rabinovitch, P.S., Kaeberlein, M., Kennedy, B.K., 2012. Rapamycin reverses elevated mTORC1 signaling in lamin A/C-deficient 
mice, rescues cardiac and skeletal muscle function, and extends survival. Sci Transl Med 4, 144ra103. Rashmi, R.N., Eckes, B., Glockner, G., Groth, M., Neumann, S., Gloy, J., Sellin, L., Walz, G., Schneider, M., Karakesisoglou, I., Eichinger, L., Noegel, A.A., 2012. The nuclear envelope protein Nesprin-2 has roles in cell proliferation and differentiation during wound healing. Nucleus 3, 172-186.

Razafsky, D., Wirtz, D., Hodzic, D., 2014. Nuclear envelope in nuclear positioning and cell migration. Adv Exp Med Biol 773, 471-490.

Reddy, K.L., Feinberg, A.P., 2013. Higher order chromatin organization in cancer. Semin Cancer Biol 23, 109-115.

Reddy, K.L., Zullo, J.M., Bertolino, E., Singh, H., 2008. Transcriptional repression mediated by repositioning of genes to the nuclear lamina. Nature 452, 243-247. Redwood, A.B., Perkins, S.M., Vanderwaal, R.P., Feng, Z., Biehl, K.J., GonzalezSuarez, I., Morgado-Palacin, L., Shi, W., Sage, J., Roti-Roti, J.L., Stewart, C.L., Zhang, J., Gonzalo, S., 2011. A dual role for A-type lamins in DNA double-strand break repair. Cell Cycle 10, 2549-2560.

Rober, R.A., Sauter, H., Weber, K., Osborn, M., 1990. Cells of the cellular immune and hemopoietic system of the mouse lack lamins A/C: distinction versus other somatic cells. J Cell Sci 95 ( Pt 4), 587-598.

Rober, R.A., Weber, K., Osborn, M., 1989. Differential timing of nuclear lamin A/C expression in the various organs of the mouse embryo and the young animal: a developmental study. Development 105, 365-378.

Roberts, P.J., Der, C.J., 2007. Targeting the Raf-MEK-ERK mitogen-activated protein kinase cascade for the treatment of cancer. Oncogene 26, 3291-3310.

Rodriguez, J., Calvo, F., Gonzalez, J.M., Casar, B., Andres, V., Crespo, P., 2010. ERK1/2 MAP kinases promote cell cycle entry by rapid, kinase-independent disruption of retinoblastoma-lamin A complexes. J Cell Biol 191, 967-979.

Rowat, A.C., Jaalouk, D.E., Zwerger, M., Ung, W.L., Eydelnant, I.A., Olins, D.E., Olins, A.L., Herrmann, H., Weitz, D.A., Lammerding, J., 2013. Nuclear envelope composition determines the ability of neutrophil-type cells to passage through micron-scale constrictions. J Biol Chem 288, 8610-8618.

Saarinen, I., Mirtti, T., Seikkula, H., Bostrom, P.J., Taimen, P., 2015. Differential Predictive Roles of A- and B-Type Nuclear Lamins in Prostate Cancer Progression. PLoS One 10, e0140671.

Sartore-Bianchi, A., Ardini, E., Bosotti, R., Amatu, A., Valtorta, E., Somaschini, A., Raddrizzani, L., Palmeri, L., Banfi, P., Bonazzina, E., Misale, S., Marrapese, G., Leone, A., Alzani, R., Luo, D., Hornby, Z., Lim, J., Veronese, S., Vanzulli, A., Bardelli, A., Martignoni, M., Davite, C., Galvani, A., Isacchi, A., Siena, S., 2016. Sensitivity to Entrectinib Associated With a Novel LMNA-NTRK1 Gene Fusion in Metastatic Colorectal Cancer. J Natl Cancer Inst 108, djv306.

Scaffidi, P., Misteli, T., 2005. Reversal of the cellular phenotype in the premature aging disease Hutchinson-Gilford progeria syndrome. Nat Med 11, 440-445.

Scaffidi, P., Misteli, T., 2008. Lamin A-dependent misregulation of adult stem cells associated with accelerated ageing. Nat Cell Biol 10, 452-459.

Schape, J., Prausse, S., Radmacher, M., Stick, R., 2009. Influence of lamin A on the mechanical properties of amphibian oocyte nuclei measured by atomic force microscopy. Biophys J 96, 4319-4325.

Scharenberg, M.A., Chiquet-Ehrismann, R., Asparuhova, M.B., 2010. Megakaryoblastic leukemia protein-1 (MKL1): Increasing evidence for an involvement in cancer progression and metastasis. Int J Biochem Cell Biol 42, 1911-1914. 
1401

1402

1403

1404

1405

1406

1407

1408

1409

1410

1411

1412

1413

1414

1415

1416

1417

1418

1419

1420

1421

1422

1423

1424

1425

1426

1427

1428

1429

1430

1431

1432

1433

1434

1435

1436

1437

1438

1439

1440

1441

1442

1443

1444

1445

1446

1447

1448

1449

1450

1451
Schreiber, K.H., Kennedy, B.K., 2013. When lamins go bad: nuclear structure and disease. Cell 152, 1365-1375.

Shin, J.W., Spinler, K.R., Swift, J., Chasis, J.A., Mohandas, N., Discher, D.E., 2013. Lamins regulate cell trafficking and lineage maturation of adult human hematopoietic cells. Proc Natl Acad Sci U S A 110, 18892-18897.

Shuang, Z.Y., Wu, W.C., Xu, J., Lin, G., Liu, Y.C., Lao, X.M., Zheng, L., Li, S., 2014. Transforming growth factor-beta1-induced epithelial-mesenchymal transition generates ALDH-positive cells with stem cell properties in cholangiocarcinoma. Cancer Lett 354, 320-328.

Shureiqi, I., Lippman, S.M., 2001. Lipoxygenase modulation to reverse carcinogenesis. Cancer Res 61, 6307-6312.

Siegel, P.M., Shu, W., Cardiff, R.D., Muller, W.J., Massague, J., 2003. Transforming growth factor beta signaling impairs Neu-induced mammary tumorigenesis while promoting pulmonary metastasis. Proc Natl Acad Sci U S A 100, 8430-8435.

Simon, D.N., Domaradzki, T., Hofmann, W.A., Wilson, K.L., 2013. Lamin A tail modification by SUMO1 is disrupted by familial partial lipodystrophy-causing mutations. Mol Biol Cell 24, 342-350.

Simon, D.N., Wilson, K.L., 2013. Partners and post-translational modifications of nuclear lamins. Chromosoma 122, 13-31.

Singh, M., Hunt, C.R., Pandita, R.K., Kumar, R., Yang, C.R., Horikoshi, N., Bachoo, R., Serag, S., Story, M.D., Shay, J.W., Powell, S.N., Gupta, A., Jeffery, J., Pandita, S., Chen, B.P., Deckbar, D., Lobrich, M., Yang, Q., Khanna, K.K., Worman, H.J., Pandita, T.K., 2013. Lamin A/C depletion enhances DNA damage-induced stalled replication fork arrest. Mol Cell Biol 33, 1210-1222.

Skvortsov, S., Schafer, G., Stasyk, T., Fuchsberger, C., Bonn, G.K., Bartsch, G., Klocker, H., Huber, L.A., 2011. Proteomics profiling of microdissected low- and highgrade prostate tumors identifies Lamin A as a discriminatory biomarker. J Proteome Res 10, 259-268.

Solovei, I., Wang, A.S., Thanisch, K., Schmidt, C.S., Krebs, S., Zwerger, M., Cohen, T.V., Devys, D., Foisner, R., Peichl, L., Herrmann, H., Blum, H., Engelkamp, D., Stewart, C.L., Leonhardt, H., Joffe, B., 2013. LBR and lamin A/C sequentially tether peripheral heterochromatin and inversely regulate differentiation. Cell 152, 584-598.

Somech, R., Shaklai, S., Geller, O., Amariglio, N., Simon, A.J., Rechavi, G., Gal-Yam, E.N., 2005. The nuclear-envelope protein and transcriptional repressor LAP2beta interacts with $\mathrm{HDAC} 3$ at the nuclear periphery, and induces histone $\mathrm{H} 4$ deacetylation. $\mathrm{J}$ Cell Sci 118, 4017-4025.

Stewart, C., Burke, B., 1987. Teratocarcinoma stem cells and early mouse embryos contain only a single major lamin polypeptide closely resembling lamin B. Cell 51, 383392.

Stoitzner, P., Pfaller, K., Stossel, H., Romani, N., 2002. A close-up view of migrating Langerhans cells in the skin. J Invest Dermatol 118, 117-125.

Stubenvoll, A., Rice, M., Wietelmann, A., Wheeler, M., Braun, T., 2015. Attenuation of Wnt/beta-catenin activity reverses enhanced generation of cardiomyocytes and cardiac defects caused by the loss of emerin. Hum Mol Genet 24, 802-813.

Sullivan, T., Escalante-Alcalde, D., Bhatt, H., Anver, M., Bhat, N., Nagashima, K., Stewart, C.L., Burke, B., 1999. Loss of A-type lamin expression compromises nuclear envelope integrity leading to muscular dystrophy. J Cell Biol 147, 913-920.

Swift, J., Ivanovska, I.L., Buxboim, A., Harada, T., Dingal, P.C., Pinter, J., Pajerowski, J.D., Spinler, K.R., Shin, J.W., Tewari, M., Rehfeldt, F., Speicher, D.W., Discher, D.E., 2013. Nuclear lamin-A scales with tissue stiffness and enhances matrix-directed differentiation. Science 341, 1240104. 
Takamori, Y., Tamura, Y., Kataoka, Y., Cui, Y., Seo, S., Kanazawa, T., Kurokawa, K., Yamada, H., 2007. Differential expression of nuclear lamin, the major component of nuclear lamina, during neurogenesis in two germinal regions of adult rat brain. Eur $\mathrm{J}$ Neurosci 25, 1653-1662.

1456 Takebe, N., Miele, L., Harris, P.J., Jeong, W., Bando, H., Kahn, M., Yang, S.X., Ivy, S.P., 2015. Targeting Notch, Hedgehog, and Wnt pathways in cancer stem cells: clinical update. Nat Rev Clin Oncol 12, 445-464.

1459

1460 Talmadge, J.E., Fidler, I.J., 2010. AACR centennial series: the biology of cancer metastasis: historical perspective. Cancer Res 70, 5649-5669.

1462

1463

1464

1465

1466 Tang, B., Vu, M., Booker, T., Santner, S.J., Miller, F.R., Anver, M.R., Wakefield, L.M., 2003. TGF-beta switches from tumor suppressor to prometastatic factor in a model of breast cancer progression. J Clin Invest 112, 1116-1124.

1467

1468

1469

1470

1471

1472

1473

1474

1475

1476

1477

1478

1479

1480

1481

1482

1483

1484

1485

1486

1487

1488

1489

1490

1491

1492

1493

1494

1495

1496

1497

1498

1499

1500

1501

1502 Tang, K., Finley, R.L., Jr., Nie, D., Honn, K.V., 2000. Identification of 12-lipoxygenase interaction with cellular proteins by yeast two-hybrid screening. Biochemistry 39, 31853191.

Ten Dijke, P., Goumans, M.J., Itoh, F., Itoh, S., 2002. Regulation of cell proliferation by Smad proteins. J Cell Physiol 191, 1-16.

Tilgner, K., Wojciechowicz, K., Jahoda, C., Hutchison, C., Markiewicz, E., 2009. Dynamic complexes of A-type lamins and emerin influence adipogenic capacity of the cell via nucleocytoplasmic distribution of beta-catenin. J Cell Sci 122, 401-413.

Trepel, J., Mollapour, M., Giaccone, G., Neckers, L., 2010. Targeting the dynamic HSP90 complex in cancer. Nat Rev Cancer 10, 537-549.

Tsai, J.H., Yang, J., 2013. Epithelial-mesenchymal plasticity in carcinoma metastasis. Genes Dev 27, 2192-2206.

Van Berlo, J.H., Voncken, J.W., Kubben, N., Broers, J.L., Duisters, R., van Leeuwen, R.E., Crijns, H.J., Ramaekers, F.C., Hutchison, C.J., Pinto, Y.M., 2005. A-type lamins are essential for TGF-beta1 induced PP2A to dephosphorylate transcription factors. Hum Mol Genet 14, 2839-2849.

van Tintelen, J.P., Tio, R.A., Kerstjens-Frederikse, W.S., van Berlo, J.H., Boven, L.G., Suurmeijer, A.J., White, S.J., den Dunnen, J.T., te Meerman, G.J., Vos, Y.J., van der Hout, A.H., Osinga, J., van den Berg, M.P., van Veldhuisen, D.J., Buys, C.H., Hofstra, R.M., Pinto, Y.M., 2007. Severe myocardial fibrosis caused by a deletion of the 5 ' end of the lamin A/C gene. J Am Coll Cardiol 49, 2430-2439.

Varela, I., Cadinanos, J., Pendas, A.M., Gutierrez-Fernandez, A., Folgueras, A.R., Sanchez, L.M., Zhou, Z., Rodriguez, F.J., Stewart, C.L., Vega, J.A., Tryggvason, K., Freije, J.M., Lopez-Otin, C., 2005. Accelerated ageing in mice deficient in Zmpste24 protease is linked to p53 signalling activation. Nature 437, 564-568.

Vargas, J.D., Hatch, E.M., Anderson, D.J., Hetzer, M.W., 2012. Transient nuclear envelope rupturing during interphase in human cancer cells. Nucleus 3, 88-100. Vaughan, A., Alvarez-Reyes, M., Bridger, J.M., Broers, J.L., Ramaekers, F.C., Wehnert, M., Morris, G.E., Whitfield, W.G.F., Hutchison, C.J., 2001. Both emerin and lamin C depend on lamin A for localization at the nuclear envelope. J Cell Sci 114, 2577-2590. Vermeulen, L., de Sousa e Melo, F., Richel, D.J., Medema, J.P., 2012. The developing cancer stem-cell model: clinical challenges and opportunities. Lancet Oncol 13, e83-89. Verstraeten, V.L., Renes, J., Ramaekers, F.C., Kamps, M., Kuijpers, H.J., Verheyen, F., Wabitsch, M., Steijlen, P.M., van Steensel, M.A., Broers, J.L., 2011. Reorganization of the nuclear lamina and cytoskeleton in adipogenesis. Histochem Cell Biol 135, 251-261. Vigouroux, C., Auclair, M., Dubosclard, E., Pouchelet, M., Capeau, J., Courvalin, J.C., Buendia, B., 2001. Nuclear envelope disorganization in fibroblasts from lipodystrophic patients with heterozygous R482Q/W mutations in the lamin A/C gene. J Cell Sci 114, 4459-4468. 
Wang, A.S., Kozlov, S.V., Stewart, C.L., Horn, H.F., 2015. Tissue specific loss of A-type

1504

1505

1506

1507

1508

1509

1510

1511

1512

1513

1514

1515

1516

1517

1518

1519

1520

1521

1522

1523

1524

1525

1526

1527

1528

1529

1530

1531

1532

1533

1534

1535

1536

1537

1538

1539

1540

1541

1542

1543

1544

1545

1546

1547

1548 lamins in the gastrointestinal epithelium can enhance polyp size. Differentiation 89, 1121.

Ward, I.M., Minn, K., van Deursen, J., Chen, J., 2003. p53 Binding protein 53BP1 is required for DNA damage responses and tumor suppression in mice. Mol Cell Biol 23, 2556-2563.

Wei, S.C., Yang, J., 2016. Forcing through Tumor Metastasis: The Interplay between Tissue Rigidity and Epithelial-Mesenchymal Transition. Trends Cell Biol 26, 111-120. Weigelin, B., Bakker, G.J., Friedl, P., 2012. Intravital third harmonic generation microscopy of collective melanoma cell invasion. IntraVital 1, 32-43.

Willis, N.D., Cox, T.R., Rahman-Casans, S.F., Smits, K., Przyborski, S.A., van den Brandt, P., van Engeland, M., Weijenberg, M., Wilson, R.G., de Bruine, A., Hutchison, C.J., 2008. Lamin A/C is a risk biomarker in colorectal cancer. PLoS One 3, e2988. Wolf, K., Te Lindert, M., Krause, M., Alexander, S., Te Riet, J., Willis, A.L., Hoffman, R.M., Figdor, C.G., Weiss, S.J., Friedl, P., 2013. Physical limits of cell migration: control by ECM space and nuclear deformation and tuning by proteolysis and traction force. $J$ Cell Biol 201, 1069-1084.

Wong, V., Pavlick, D., Brennan, T., Yelensky, R., Crawford, J., Ross, J.S., Miller, V.A., Malicki, D., Stephens, P.J., Ali, S.M., Ahn, H., 2016. Evaluation of a Congenital Infantile Fibrosarcoma by Comprehensive Genomic Profiling Reveals an LMNA-NTRK1 Gene Fusion Responsive to Crizotinib. J Natl Cancer Inst 108, djv307.

Wood, A.M., Rendtlew Danielsen, J.M., Lucas, C.A., Rice, E.L., Scalzo, D., Shimi, T., Goldman, R.D., Smith, E.D., Le Beau, M.M., Kosak, S.T., 2014. TRF2 and lamin A/C interact to facilitate the functional organization of chromosome ends. Nat Commun 5, 5467.

Wu, M.Y., Hill, C.S., 2009. Tgf-beta superfamily signaling in embryonic development and homeostasis. Dev Cell 16, 329-343.

Wu, Z., Wu, L., Weng, D., Xu, D., Geng, J., Zhao, F., 2009. Reduced expression of lamin $\mathrm{A} / \mathrm{C}$ correlates with poor histological differentiation and prognosis in primary gastric carcinoma. J Exp Clin Cancer Res 28, 8.

Yu, H., Mouw, J.K., Weaver, V.M., 2011. Forcing form and function: biomechanical regulation of tumor evolution. Trends Cell Biol 21, 47-56.

Zhang, Y.Q., Sarge, K.D., 2008. Sumoylation regulates lamin A function and is lost in lamin A mutants associated with familial cardiomyopathies. J Cell Biol 182, 35-39. Zhong, N., Radu, G., Ju, W., Brown, W.T., 2005. Novel progerin-interactive partner proteins hnRNP E1, EGF, Mel 18, and UBC9 interact with lamin A/C. Biochem Biophys Res Commun 338, 855-861.

Zuela, N., Zwerger, M., Levin, T., Medalia, O., Gruenbaum, Y., 2016. Impaired mechanical response of an EDMD mutation leads to motility phenotypes that are repaired by loss of prenylation. J Cell Sci 129, 1781-1791.

Zuo, B., Yang, J., Wang, F., Wang, L., Yin, Y., Dan, J., Liu, N., Liu, L., 2012. Influences of lamin A levels on induction of pluripotent stem cells. Biol Open 1, 1118-1127.

Zwerger, M., Jaalouk, D.E., Lombardi, M.L., Isermann, P., Mauermann, M., Dialynas, G., Herrmann, H., Wallrath, L.L., Lammerding, J., 2013. Myopathic lamin mutations impair nuclear stability in cells and tissue and disrupt nucleo-cytoskeletal coupling. Hum Mol

1549 Genet 22, 2335-2349. 


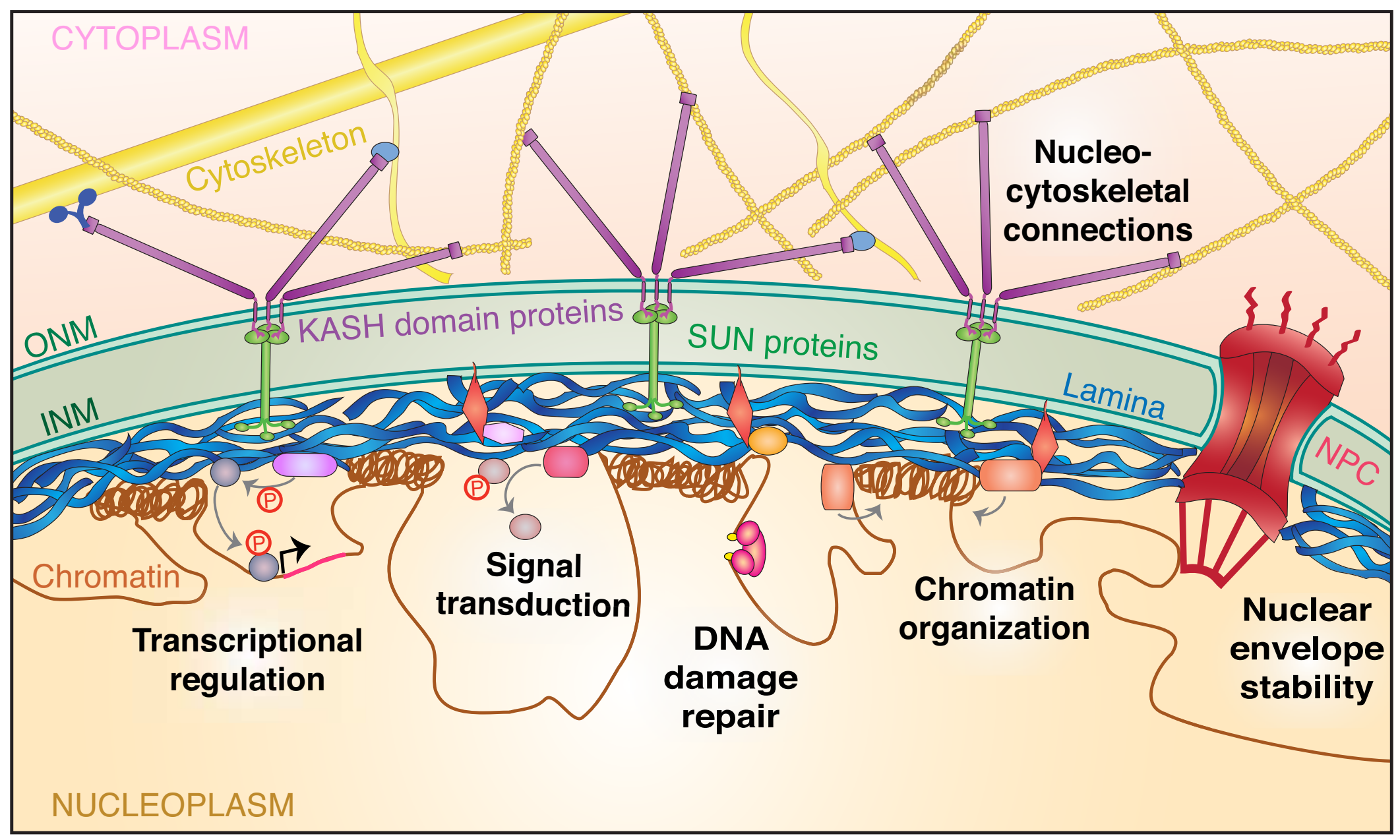




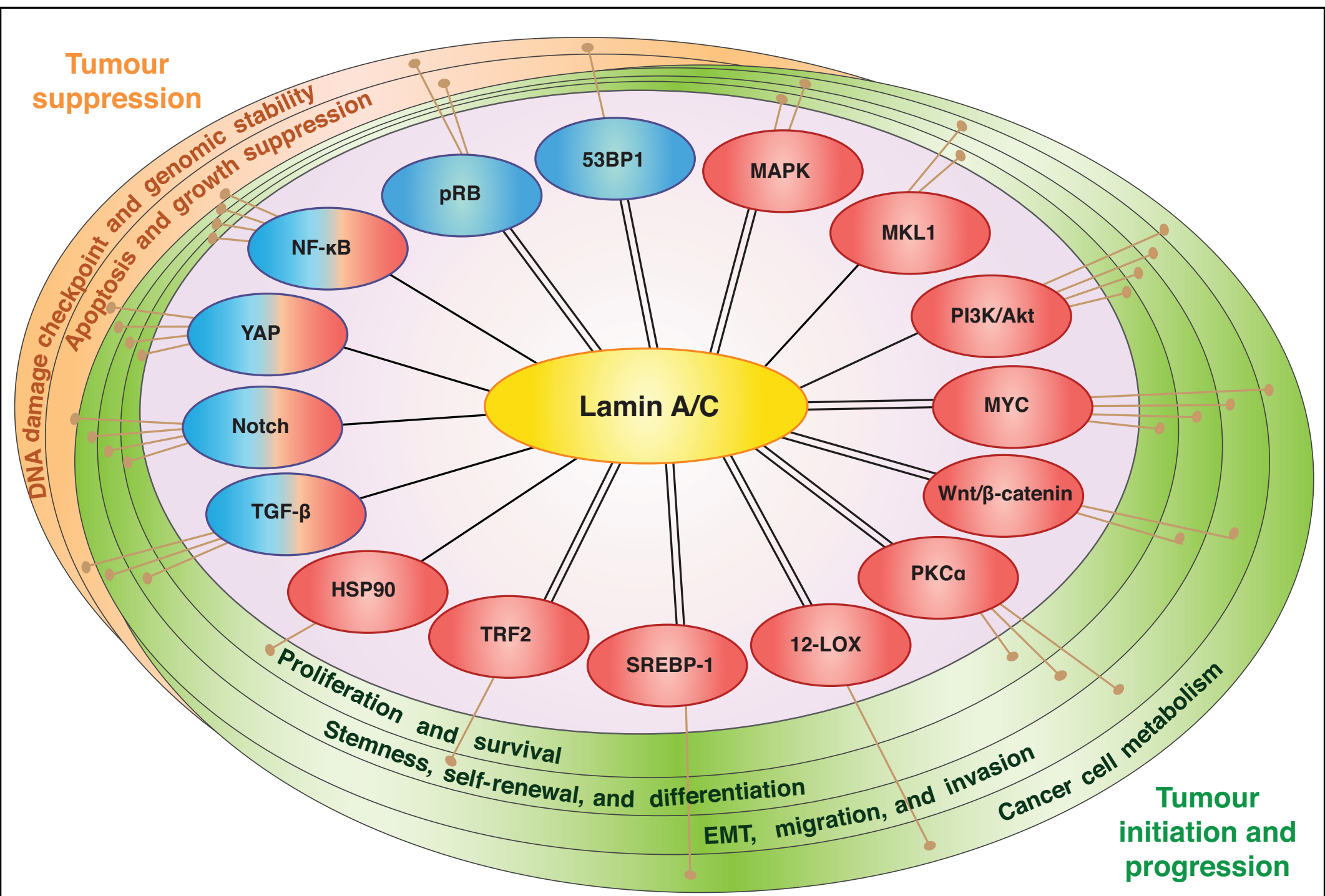




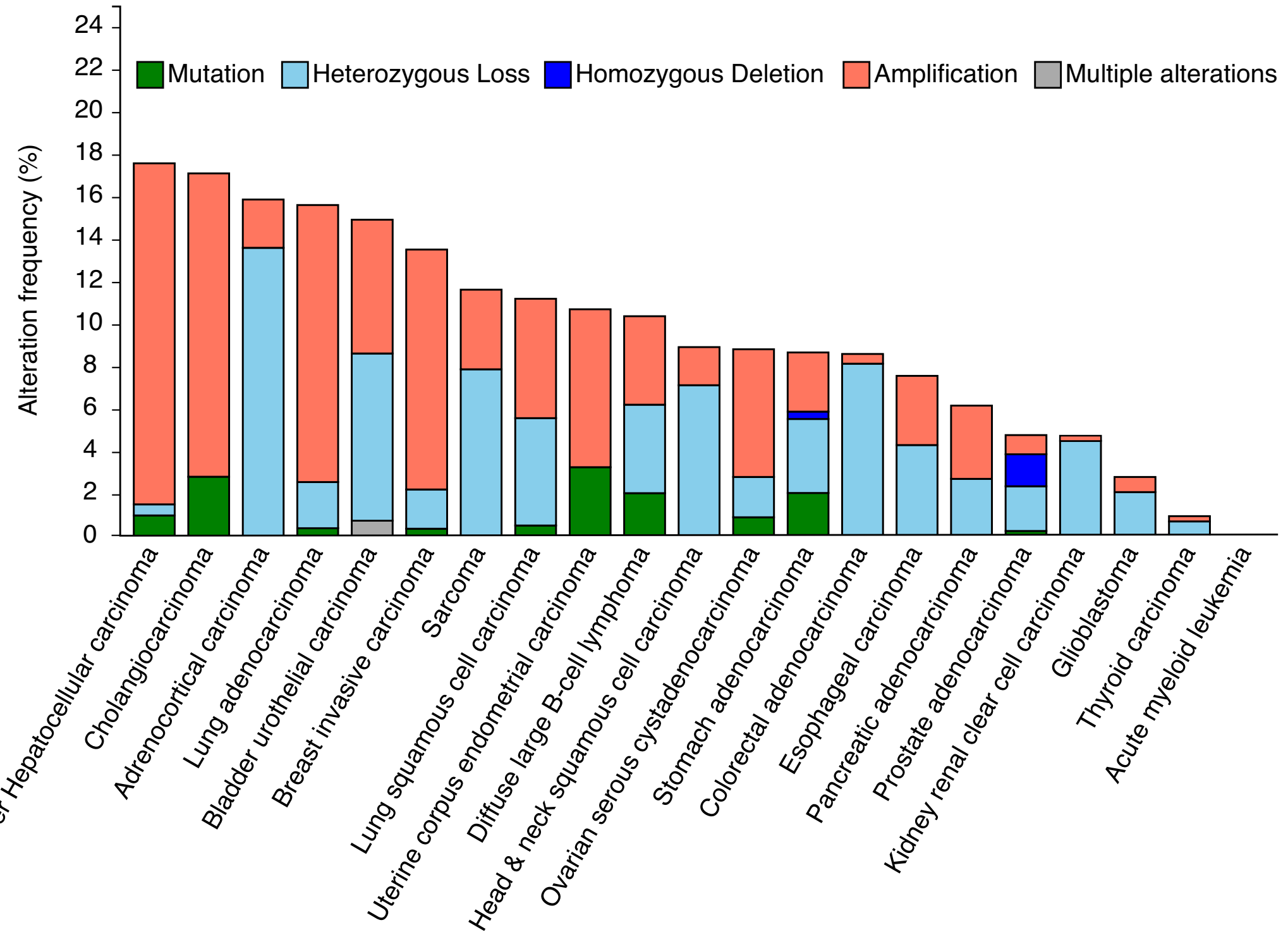




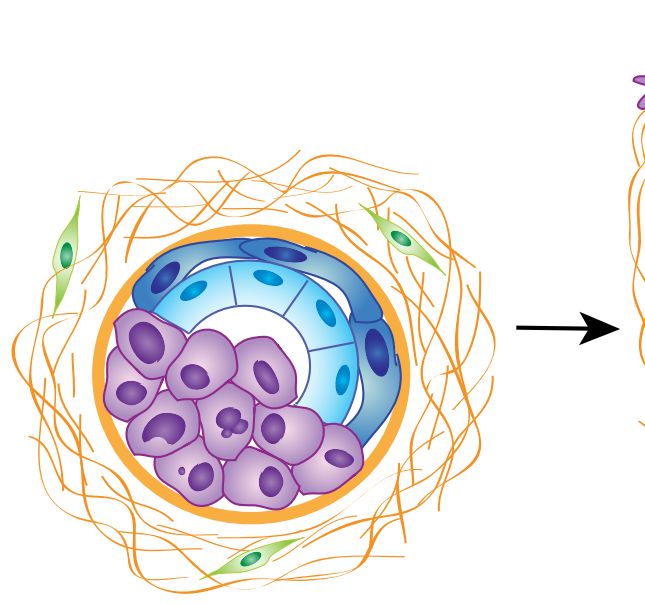

Tumour initiation and outgrowth

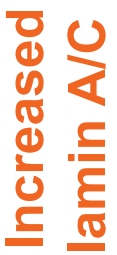

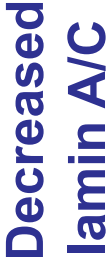

- Increased genomic instability

- Decreased pRB-mediated growth suppression

- Hyperactivation of MAPK proliferative signalling
Invasion and survival in circulation

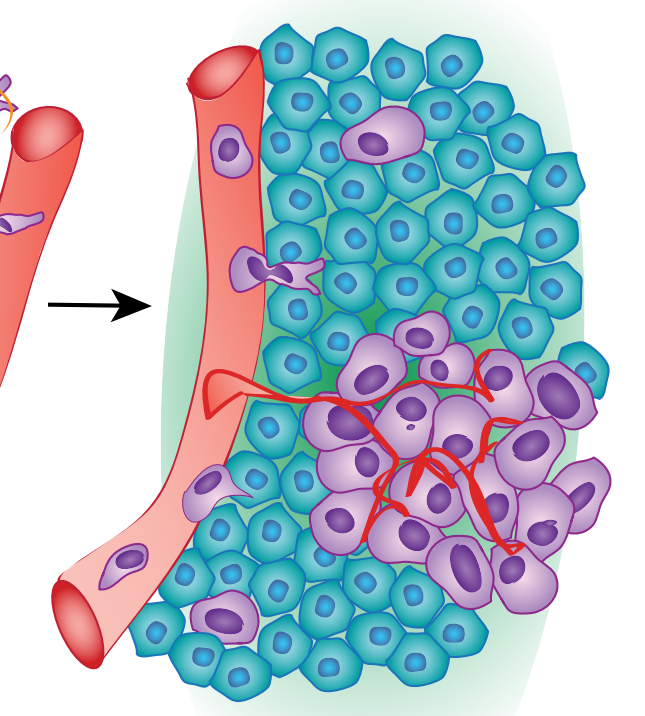

Metastatic growth and therapeutic resistance

- Decreased susceptibility to DNA damaging agents

polarized migration

- MKL1-dependent gene expression promotes cytoskeleton dynamics and migration

- Increased stemness through $\beta$-catenin activity

- Anti-apoptotic NF-KB

- Resistance to mechanical stress

- Increased nuclear deformability for migration through confined spaces

- Modulation of TGF- $\beta$ signalling to promote EMT over growth suppression functions promote chemoresistance

- Increased stem cell characteristics through loss of heterochromatin

- Increased ECM deposition for microenvironment remodelling 